\title{
Recovery of Fatty Acids from Mineralogic Mars Analogs by TMAH Thermochemolysis for the Sample Analysis at Mars Wet Chemistry Experiment on the Curiosity Rover
}

\author{
Amy J. Williams, ${ }^{1,2,3,{ }^{*}}$ Jennifer Eigenbrode, ${ }^{3}$ Melissa Floyd, ${ }^{3}$ Mary Beth Wilhelm, ${ }^{4}$ \\ Shane O'Reilly, ${ }^{5,6}$ Sarah Stewart Johnson, ${ }^{7}$ Kathleen L. Craft, ${ }^{8}$ Christine A. Knudson, ${ }^{3,9}$ \\ Slavka Andrejkovičová, ${ }^{3,9}$ James M.T. Lewis, ${ }^{3,10}$ Arnaud Buch, ${ }^{11}$ Daniel P. Glavin, ${ }^{3}$ \\ Caroline Freissinet, ${ }^{12}$ Ross H. Williams, ${ }^{3,9}$ Cyril Szopa, ${ }^{12}$ Maëva Millan, ${ }^{3,7}$ Roger E. Summons, ${ }^{5}$ \\ Amy McAdam, ${ }^{3}$ Kathleen Benison, ${ }^{13}$ Rafael Navarro-González, ${ }^{14}$ \\ Charles Malespin, ${ }^{3}$ and Paul R. Mahaffy ${ }^{3}$
}

\begin{abstract}
The Mars Curiosity rover carries a diverse instrument payload to characterize habitable environments in the sedimentary layers of Aeolis Mons. One of these instruments is Sample Analysis at Mars (SAM), which contains a mass spectrometer that is capable of detecting organic compounds via pyrolysis gas chromatography mass spectrometry (py-GC-MS). To identify polar organic molecules, the SAM instrument carries the thermochemolysis reagent tetramethylammonium hydroxide (TMAH) in methanol (hereafter referred to as TMAH). TMAH can liberate fatty acids bound in macromolecules or chemically bound monomers associated with mineral phases and make these organics detectable via gas chromatography mass spectrometry (GC-MS) by methylation. Fatty acids, a type of carboxylic acid that contains a carboxyl functional group, are of particular interest given their presence in both biotic and abiotic materials. This work represents the first analyses of a suite of Mars-analog samples using the TMAH experiment under select SAM-like conditions. Samples analyzed include iron oxyhydroxides and iron oxyhydroxysulfates, a mixture of iron oxides/oxyhydroxides and clays, iron sulfide, siliceous sinter, carbonates, and shale. The TMAH experiments produced detectable signals under SAM-like pyrolysis conditions when organics were present either at high concentrations or in geologically modern systems. Although only a few analog samples exhibited a high abundance and variety of fatty acid methyl esters (FAMEs), FAMEs were detected in the majority of analog samples tested. When utilized, the
\end{abstract}

\footnotetext{
${ }^{1}$ Department of Physics, Astronomy, and Geosciences, Towson University, Towson, Maryland, USA.

${ }^{2}$ Center for Research and Exploration in Space Sciences and Technology/University of Maryland Baltimore County, Baltimore, Maryland, USA.

${ }^{3}$ Space Science Exploration Division (Code 690), NASA Goddard Space Flight Center, Greenbelt, Maryland, USA.

${ }^{4}$ NASA Ames Research Center, Mountain View, California, USA.

${ }^{5}$ Department of Earth, Atmospheric and Planetary Sciences, Massachusetts Institute of Technology, Cambridge, Massachusetts, USA.

${ }^{6}$ School of Earth Sciences, University College Dublin, Dublin, Ireland.

${ }^{7}$ Department of Biology, Georgetown University, Washington, DC, USA.

${ }^{8}$ Johns Hopkins University Applied Physics Laboratory, Laurel, Maryland, USA.

${ }^{9}$ Center for Research and Exploration in Space Sciences and Technology/University of Maryland College Park, College Park, Maryland, USA.

${ }^{10}$ Universities Space Research Association, Columbia, Maryland, USA.

${ }^{11}$ Laboratoire de Génie des Procédés et Matériaux, CentraleSupelec, Gif sur Yvette, France.

${ }^{12}$ CNRS-UVSQ Laboratoire Atmosphères Milieux Observations Spatiales LATMOS, Guyancourt, France.

${ }_{13}^{13}$ Department of Geology and Geography, West Virginia University, Morgantown, West Virginia, USA.

${ }^{14}$ Instituto de Ciencias Nucleares, Universidad Nacional Autonoma de Mexico, Circuito Exterior, Ciudad Universitaria, Ciudad de Mexico, Mexico.

*Current affiliation: Department of Geological Sciences, University of Florida, Gainesville, Florida, USA.
}

(C) Amy J. Williams et al., 2019; Published by Mary Ann Liebert, Inc. This Open Access article is distributed under the terms of the Creative Commons License (http://creativecommons.org/licenses/by/4.0), which permits unrestricted use, distribution, and reproduction in any medium, provided the original work is properly credited. 
TMAH thermochemolysis experiment on SAM could be an opportunity to detect organic molecules bound in macromolecules on Mars. The detection of a FAME profile is of great astrobiological interest, as it could provide information regarding the source of martian organic material detected by SAM. Key Words: MarsSample Analysis at Mars (SAM) instrument-Molecular biosignatures-TMAH-MSL_FAME. Astrobiology $19,522-546$.

\section{Introduction}

$\mathbf{T}$ HE ONGOING EXPLORATION of Gale Crater by the NASA Mars Curiosity rover has modernized our understanding of martian geochemistry (Glavin et al., 2013; McLennan et al., 2014; Ming et al., 2014; Anderson et al., 2015; Freissinet et al., 2015; Mangold et al., 2016; Eigenbrode et al., 2018), mineralogy (McAdam et al., 2014; Vaniman et al., 2014; Sutter et al., 2017), sedimentology (Williams et al., 2013; Edgar et al., 2017; Mangold et al., 2017), modern aeolian processes (Bridges et al., 2017; Cousin et al., 2017), planetary evolution (Atreya et al., 2013; Mahaffy et al., 2015), and potential for the presence of habitable environments (Grotzinger et al., 2014). Ancient terrains on Mars continue to be sites of great astrobiological interest, and future missions such as the joint ESA-Roscosmos 2020 ExoMars rover and the NASA Mars2020 rover will be equipped to search for signs of past life on Mars (Mustard et al., 2013). One of the promising techniques for life detection is wet chemistry pyrolysis gas chromatography mass spectrometry (py-GC-MS), which is available on the Curiosity rover as part of the Sample Analysis at Mars (SAM) instrument. Thermal volatilization gas chromatography mass spectrometry (TVGC-MS) techniques limited to $500^{\circ} \mathrm{C}$ without wet chemistry capabilities have been utilized in the past by the Viking landers (Biemann et al., 1977), and TV-MS and wet chemistry experiments limited to $500^{\circ} \mathrm{C}$ were utilized by the Phoenix lander (Boynton et al., 2001). Py-GC-MS will again be used on the upcoming ExoMars rover as part of the Mars Organic Molecule Analyzer (MOMA) instrument (Goetz et al., 2016; Goesmann et al., 2017). The SAM suite configuration includes a tunable laser spectrometer (TLS), quadrupole mass spectrometer (QMS), gas chromatograph (GC), and the capability to perform wet chemistry (derivatization and thermochemolysis) analyses (Mahaffy et al., 2012). The SAM Sample Manipulation System (SMS) carousel contains 74 individual sample cups housed within two concentric rings of the carousel. Nine of these cups are slated for wet chemistry experiments and contain reagents for either thermochemolysis (two cups with tetramethylammonium hydroxide [TMAH] in methanol) or derivatization (seven cups with $N$-methyl- $N$-tertbutyldimethylsilyl-trifluoroacetamide [MTBSTFA] in dimethylformamide [DMF], hereafter referred to together as MTBSTFA).

Wet chemistry experiments aim to transform polar organic molecules (e.g., carboxylic acids) into volatile derivatives that are amenable and detectable by gas chromatography mass spectrometry (GC-MS) (Metcalffe and Wang, 1981; del Rio et al., 1996), as well as freeing bound components of larger macromolecules otherwise undetectable with GC-MS (Grasset et al., 2002), if the macromolecule has hydrolysable units of appropriate size. Thermochemolysis, in this case thermal hydrolysis and methylation, with TMAH has been used for several decades in a variety of terrestrial fields of study, including soil sciences (Schulten, 1996; Chefetz et al., 2000; Deport et al., 2006), petroleum geochemistry (Larter and Horsfield, 1993), and sedimentology (Pulchan et al., 1997; Guignard et al., 2005; Remusat et al., 2005; Anderson et al., 2015). When strongly basic TMAH in methanol is added to a sample with membrane-bound phospholipids and heated, the phospholipids will undergo transesterification, liberating the fatty acids from their glycerol backbone. This creates a fatty acid carboxyl group which will be methylated to form a fatty acid methyl ester, or FAME (Fig. 1). FAMEs are more volatile than non-methylated fatty acids and therefore more amenable to detection by GC-MS.

Fatty acids are ubiquitous and abundant constituents of bacterial and eukaryotic cellular membranes, bound in phospholipids and glycolipids (Vestal and White, 1989). Carboxylic acids have also been identified in exogenous carbonaceous material, for example having been detected in the Murchison meteorite (Cronin et al., 1993). In addition, lipids are common constituents of Mars analog environments on Earth (Parenteau et al., 2014; Tan et al., 2018). Biotic and abiotic carboxylic acids produce distinctly different GC-MS patterns. Fatty acids derived from microbial cellular metabolic processes have an even-over-odd carbon chain length preference due to enzymatically formed acetyl $\left(\mathrm{C}_{2}\right)$ units derived from glucose (Volkman, 2006). In contrast, abiotic fatty acid patterns will favor shorter carbon chain lengths with no carbon preference (Bray and Evans, 1961; McCollom et al., 1999). It is important to note that the even-over-odd carbon chain preference may be solely linked to terrestrial bacteria and may not reflect the carbon number chain preference of an extraterrestrial organism. In addition, very short chain carboxylic acids can be metabolic byproducts that were not incorporated into cellular membranes. Therefore, with some level of accepted uncertainty, characteristics of a FAME profile could be used to deconvolve the origin of fatty acids detected on Mars (Eigenbrode et al., 2011). FAME profiles have been used to explore microbial communities and preservation in terrestrial environments such as soils (Zelles, 1999; Ritchie et al., 2000; Wilhelm et al., 2017), acid mine drainage sediments (BenDavid et al., 2004), carbonate nodules in freshwater stromatolites (Brady et al., 2010), and shales (del Rio et al., 1996; Blokker et al., 2000).

Figure 2 shows the SAM suite, SMS, and wet chemistry cups. Of the 74 sample cups housed within the SAM SMS carousel, two wet chemistry cups contain $0.5 \mathrm{~mL}$ total of TMAH in methanol $(1: 3 \mathrm{v} / \mathrm{v})$, mixed with two recovery standards (1-fluoronaphthalene [34 nmol] and pyrene [25 nmol]), and nonanoic acid as an internal calibration standard. The nonanoic acid internal standard (ca. $12.5 \mathrm{nmol})$ is isolated from the TMAH inside a separate hermetically sealed internal foilcapped reservoir until the time of the thermochemolysis experiment in order to test the TMAH reaction efficiency. These cups were welded closed under $\mathrm{N}_{2}$ atmosphere to preserve the 

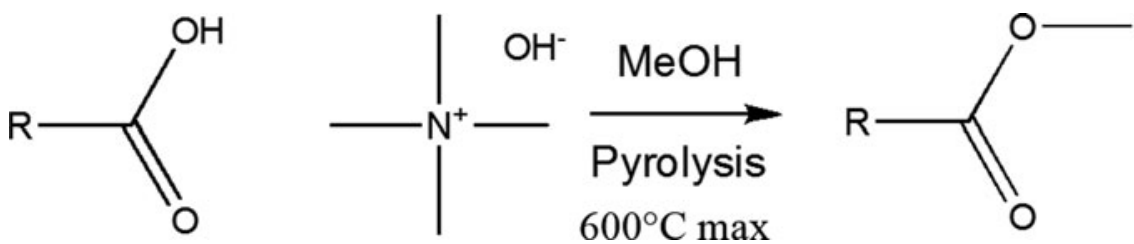

\section{$+\mathrm{N}\left(\mathrm{CH}_{3}\right)_{3}$}

FIG. 1. Schematic of the thermochemolysis reaction between a generic carboxylic acid (either a free fatty acid or membrane-bound fatty acid liberated from a macromolecule) and TMAH. Methanol is the solvent. The carboxylic acid is methylated at between $400^{\circ} \mathrm{C}$ and $600^{\circ} \mathrm{C}$, and TMA is generated as a by-product.

TMAH over the lifetime of the mission. As with the MTBSTFA experiment, pyrene is used as a recovery standard to ensure that the cup was fully punctured and the solvent was carried to the GC-MS. Additional details of the MTBSTFA experiment are presented elsewhere (Mahaffy et al., 2012; Stalport et al., 2012).

SAM carries six GC columns: four columns are dedicated to organics detection, and two are designed for very light hydrocarbon or small inorganic molecule analyses (Table 1). Of the organic-specific columns, GC1 (MXT-20) and GC5 (MXT-CLP) are both designed for medium molecular weight $\left(\mathrm{C}_{5}-\mathrm{C}_{15}\right)$ organics, GC2 $(\mathrm{MXT}-5)$ is designed for high molecular weight $\left(>\mathrm{C}_{15}\right)$ organics and derivative products, and GC4 (Chirasil- $\beta$-Dex CB) is designed to resolve enantiomers. When the TMAH experiment is conducted on Mars, the cup will be punctured with a pin located on the outer ring of the SMS. After puncture of the cup foils, the inner and outer reservoirs will mix to expose the nonanoic internal standard to the solvents, and the cup will rotate into position to receive the solid sample, composed of either the $1 \mathrm{~mm}$ or $<150 \mu \mathrm{m}$ size fraction of powdered drill fines, up to a volume of $790 \mu \mathrm{L}$. With solid sample delivery complete, the cup will be raised and sealed to the SAM pyrolysis oven. The cup will then be heated at $35^{\circ} \mathrm{C} \mathrm{min}-1$ from ambient to no higher than $600^{\circ} \mathrm{C}$ (the final temperature is still under development). Methylated thermochemolysis products will first be concentrated on the SAM hydrocarbon trap under He carrier gas flow at a rate of $\sim 0.03 \mathrm{~atm}-\mathrm{cc} / \mathrm{s}$ and then either concentrated on a GC injection trap that can be flash heated in order to quickly inject into the GC column (GC4 or GC5) or flow directly to a GC column (GC1 or $\mathrm{GC2}$ ) at $0.9 \mathrm{~mL} \mathrm{~min}^{-1}$. The SAM hydrocarbon trap contains three adsorbents in the following order: $490 \mathrm{mg}$ of $0.38 \mathrm{~mm}$ non-porous silica beads, $79 \mathrm{mg}$ of $60 / 80$ mesh Tenax TA, and $110 \mathrm{mg}$ of 60/80 Carbosieve G (Mahaffy et al., 2012). The gases will be trapped in the direction starting with the silica beads and ending with the Carbosieve G. The trap will then be heated and the gas flow reversed to release the trapped material. The adsorbed gases will be driven through one or more GC columns. The injection trap is composed of either Tenax GR (for GC4 and GC5) or Carbosieve III (for GC6). The methylated products are transferred to the cold trap, and the trap is flash heated to $\sim 310^{\circ} \mathrm{C}$ (over $5-10 \mathrm{~s}$ ) to release the products to one of the GC columns designed for

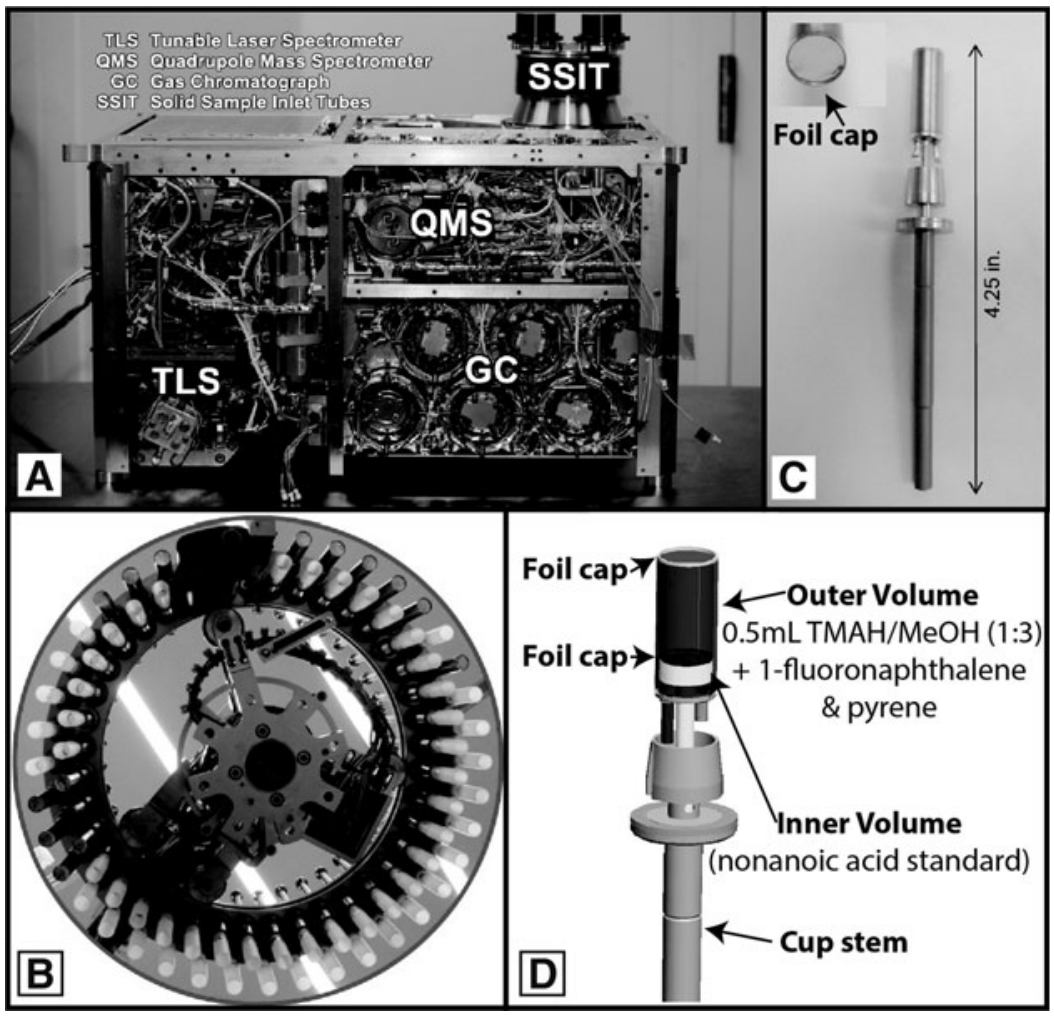

FIG. 2. (A) The SAM instrument suite with side panels removed. (B) Examples of the foil-capped metal cups for wet chemistry experiments and the quartz cups for standard mass spectrometry analysis of solid samples. (C) A foil-capped wet chemistry cup (image of foil cap in inset). (D) Interior schematic of wet chemistry cup. 
Table 1. Gas Chromatograph Columns on SAM

\begin{tabular}{ll}
\hline Column & \multicolumn{1}{c}{ Species Targeted } \\
\hline GC1 - MXT-20 (WCOT) & Medium molecular weight organics $\left(\mathrm{C}_{5}-\mathrm{C}_{15}\right.$ organics $)$ \\
GC2 - MXT-5 (WCOT) & High molecular weight VOCs including $>\mathrm{C}_{15}$ chemical derivatives \\
GC3 - Carbobond (PLOT) & Permanent gases and $\mathrm{C}_{1}-\mathrm{C}_{2}$ hydrocarbons \\
GC4 - Chirasil- $\beta$ Dex CB & Enantiomers of VOCs \\
GC5 - MXT-CLP (WCOT) & Medium molecular weight organics $\left(\mathrm{C}_{5}-\mathrm{C}_{15}\right.$ organics $)$ \\
GC6 - MXT-Q (PLOT) & $\mathrm{C}_{1}-\mathrm{C}_{4}$ VOCs, $\mathrm{NH}_{3}, \mathrm{~S}$-containing compounds \\
\hline
\end{tabular}

$\mathrm{WCOT}=$ wall-coated open tubular, VOC $=$ volatile organic compounds, PLOT $=$ porous layer open tubes.

organics, in a sharp injection for a better GC separation. Once in the GC column of choice, the products are separated by using a column heating ramp up to $180-250^{\circ} \mathrm{C}$. Methylated products will be identified based on their retention times and mass spectra as determined by the SAM QMS.

Here, we report the first GC-MS results of FAMEs produced from a selection of Mars-analog materials using a thermochemolysis procedure that approximates certain aspects of the SAM thermochemolysis wet chemistry experiment. Table 2 summarizes the main differences in conditions between the benchtop experimental approach used in this work and the SAM flight model. The goal of this study was to determine the recovery of FAMEs from a suite of rocks and sediments of various ages, including some samples considered mineralogic analogs to mineral suites observed on Mars. Utilizing Mars-analog samples will allow for contextualized results from the in situ experiment on Mars and provide valuable insight and testing of a wet chemistry technique slated for use on future flight instruments. Understanding the impact of mineralogical variations on thermal extraction and methylation is also of great importance (Ming et al., 2009; Navarro-González et al., 2010; Glavin et al., 2013; Lewis et al., 2015, 2018; Buch et al., 2018). Fatty acids are the focus of this study (1) to provide a limited suite of organic compounds that may exhibit a large molecular weight range and (2) because TMAH thermochemolysis directly targets both free fatty acids and those bound in membranes. Results will reveal which mineral matrices have a positive or deleterious effect on the recovery of FAMEs through thermochemolysis experiments on a SAM-like benchtop system, defined in this work as using a SAM-like pyrolysis oven ramp of $35^{\circ} \mathrm{C} \mathrm{min}^{-1}$ and SAM-comparable GC column and oven program with a commercial pyrolyzer and GC-MS. As a comparison to the SAM-like pyrolysis ramp, a $500^{\circ} \mathrm{C}$ flash pyrolysis method was used with the same procedure to determine how $500^{\circ} \mathrm{C}$ flash versus $35^{\circ} \mathrm{C} \mathrm{min}^{-1}$ ramped pyrolysis affects FAME detection in the analog samples. Other "SAM-like" variables will be optimized in future work, such as He pressure, split, trap operation, and oven-trap gas processing system path length/temperature; therefore, those tests are outside the scope of this work. The work presented here will inform optimal sample selection in Gale Crater for employing this technique in situ.

\section{Materials and Methods}

\subsection{Analog samples and sample preparation}

One cryoconite organic working sample, one procedural blank, and 13 terrestrial samples (Table 3) considered to have mineralogical relevance to martian environments of astrobiological interest were selected for this study and provide a variety of mineralogies that Curiosity could encounter in Gale Crater. Details on analog site sampling and sample preparation are in the Supplementary Materials (available at https://www.liebertpub.com/suppl/doi/10.1089/ ast.2018.1819).

Total carbon and total organic carbon (TOC) were quantified by using a loss on ignition procedure on a Shimadzu TOC-Vcsh $\mathrm{NC}$ analyzer (detection limit $0.03-2.00 \mathrm{mg}$ absolute, $\pm 0.06 \%$ error). Sample mineralogy (Table 3) was determined on either a

Table 2. Comparison of Operating Conditions for Benchtop Experiments versus THE SAM FLIGHT INSTRUMENT

\begin{tabular}{|c|c|c|}
\hline & Benchtop py-GC-MS & SAM Flight Model \\
\hline Pyrolysis conditions & $\begin{array}{l}35^{\circ} \mathrm{C} \min ^{-1} \text { or } 500^{\circ} \mathrm{C} \text { flash pyrolysis } \\
800^{\circ} \mathrm{C} \text { max stable oven temp }\end{array}$ & $\begin{array}{l}35^{\circ} \mathrm{C} \min ^{-1} \\
950-1100^{\circ} \mathrm{C} \text { max oven temp depending on oven }\end{array}$ \\
\hline Pyrolysis cup & Stainless steel cup & Stainless steel cup \\
\hline Column Flow & $3 \mathrm{~mL} \min ^{-1}$ & $\sim 0.9 \mathrm{~mL} \mathrm{~min}^{-1}$ \\
\hline Trap & $\begin{array}{l}\text { In series: silica wool, Tenax TA, } \\
\text { silica wool }\end{array}$ & In series: Silica beads, Tenax TA, Carbosieve G \\
\hline Trap/Inlet Heater & $300-310^{\circ} \mathrm{C}$ & $>350^{\circ} \mathrm{C}$ \\
\hline Transfer Line Temperature & $135^{\circ} \mathrm{C}$ or $270^{\circ} \mathrm{C}$ & $135^{\circ} \mathrm{C}$ \\
\hline GC column & Restek MXT-CLP (GC5 comparable) & See column options in Table 1 \\
\hline \multirow{3}{*}{ GC conditions } & Vary: & Vary: \\
\hline & From $\sim 35^{\circ} \mathrm{C}$ to $300^{\circ} \mathrm{C}$ & $\begin{array}{l}\text { From } \sim 10^{\circ} \mathrm{C} \text { to } \max 160-260^{\circ} \mathrm{C} \\
\text { depending on column }\end{array}$ \\
\hline & $\begin{array}{l}\text { Ramp at } 5^{\circ} \mathrm{C} \min ^{-1} \text { or } 10^{\circ} \mathrm{C} \min ^{-1} \\
\text { as desired }\end{array}$ & $\operatorname{Ramp}$ at $5^{\circ} \mathrm{C} \min ^{-1}$ or $10^{\circ} \mathrm{C} \min ^{-1}$ as desired \\
\hline
\end{tabular}




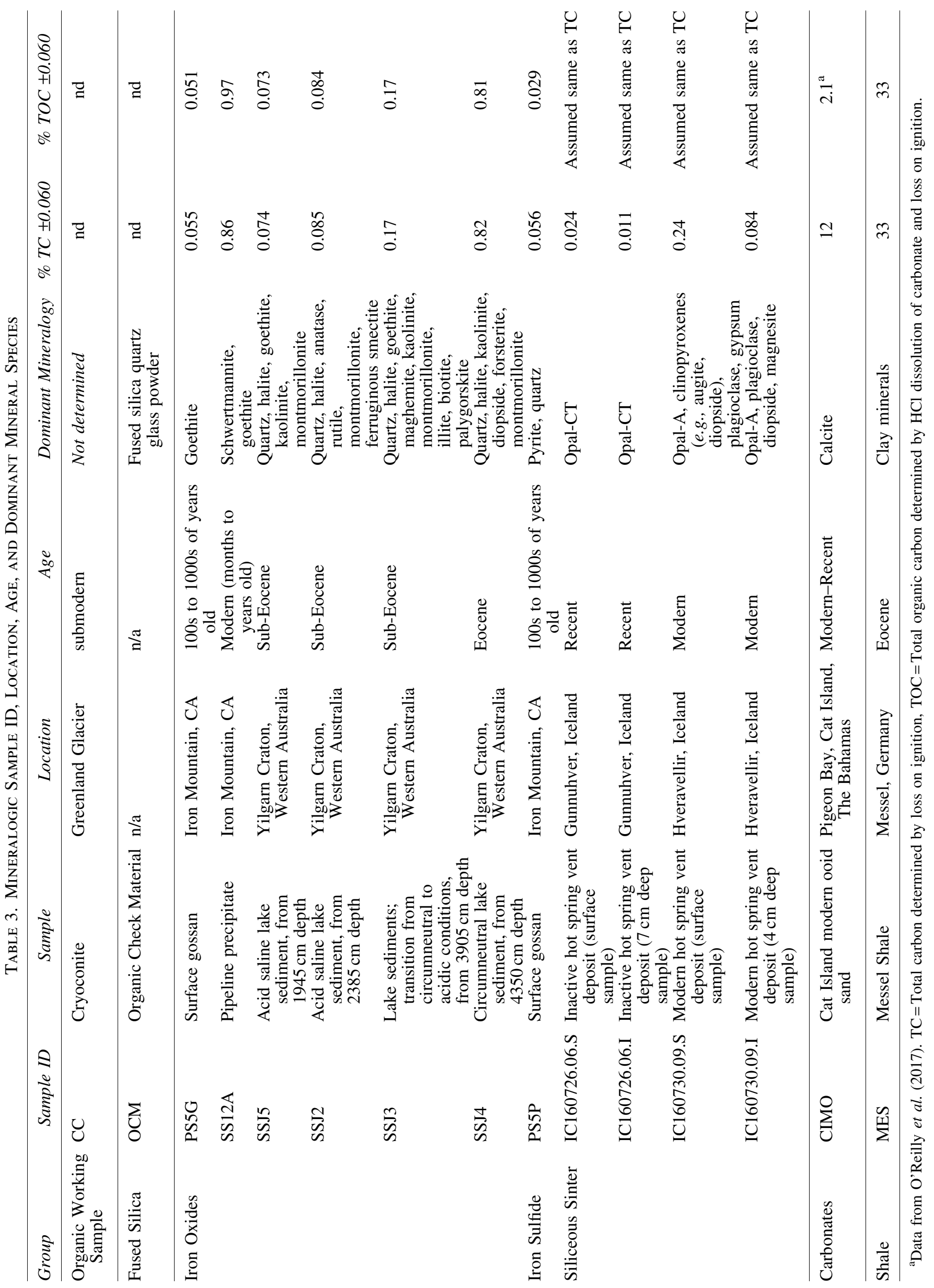


Bruker D8 Discover X-ray diffractometer or a Rigaku Ultima IV X-ray diffractometer. Samples were scanned from $2^{\circ}$ to $64^{\circ}$ $2 \theta$. The measured patterns were then compared to standard mineral patterns from the RRuff repository (Downs, 2006) and the International Centre for Diffraction Data (ICDD) files with PDXL software as well as Materials Data Incorporated (MDI) Jade software to characterize the sample mineralogies.

Cryoconite was chosen as the organic working sample with a natural mixture of organic molecules for repeated analyses of py-GC-MS parameters. This cryoconite is a contemporary organic-rich aeolian dust deposit containing mixed living microbial communities with deceased biomass, anthropogenic soot, and micrometer-scale rock particles from Friedrichsbreen glacier in Svalbard.

A fused silica powder (FS120, HP Technical Ceramics, LTD, $250-125 \mu \mathrm{m}$ ) was heated to $550^{\circ} \mathrm{C}$ for $8 \mathrm{~h}$ in air to combust all organics, including plastic polymers, and was used as a procedural blank. It was processed in the same manner as the organic working sample and analog samples (Mahaffy et al., 2012). The same material is carried on board Curiosity as the Organic Check Material (OCM) and can be used as a procedural blank to quantify any organic contamination from the sample handling system (Conrad et al., 2012; Mahaffy et al., 2012).

Select iron-rich samples were collected from the Iron Mountain massive sulfide deposit near Redding, California (Williams et al., 2015). The massive sulfide surface exposure, also known as a gossan, consists predominantly of goethite with minor hematite and residual pyrite, and represents an acidic and saline system (Williams et al., 2015; Jacobs et al., 2016). The age of the modern surface gossan is not known and therefore is referred to here as "older," for example, hundreds to thousands of years old.

Modern iron-rich precipitate was collected along an acid mine effluent pipeline at Iron Mountain. The pipeline carries pH 2.5-3.0 acid mine drainage water, and within the pipeline microbial oxidation of the iron-rich fluids creates an $\mathrm{Fe}(\mathrm{III})$-rich schwertmannite mineral precipitate (Williams et al., 2017).

Modern to Eocene-age mixed iron oxyhydroxides, halite, gypsum, quartz, and clay mineral bearing sediments were collected from an acid to circumneutral saline lake sediment core in the Norseman region, Yilgarn Craton, Western Australia. Sample SSJ5 was collected from $1945 \mathrm{~cm}$ depth, SSJ2 was collected from $2385 \mathrm{~cm}$ depth, SSJ3 was collected from $3905 \mathrm{~cm}$ depth, and SSJ4 was collected from $4350 \mathrm{~cm}$ depth. These iron-rich samples from the United States and Australia are considered to be mineralogically analogous to saline and circumneutral or acidic iron-dominated environments on Mars such as Meridiani Planum (Klingelhofer et al., 2004; Benison and Bowen, 2006), and possibly the Vera Rubin Ridge (hematite-bearing unit) in Gale Crater (Fraeman et al., 2013, 2016; Williams et al., 2015).

Hot spring sinter deposits reported here are analogous to sinter deposits from deep-seated volcanically driven hydrothermal systems detected in Nili Patera, Mars (Skok, 2010). Actively forming sinter was collected from the Hveravellir hot spring, Iceland. A surface sample and $4 \mathrm{~cm}$ deep sample were collected from the modern lower vent. Sinter from an inactive but still hot spring mound was collected at the Gunnuhver hot springs, Iceland. A surface sample and $7 \mathrm{~cm}$ deep sample were collected from a lower vent sinter deposit.
Although extensive carbonate deposits have not been identified on Mars (Albee et al., 2001), evidence for calcium carbonate has been found at the polar Phoenix landing site (Boynton et al., 2009), and regionally limited deposits of hydrothermal magnesium-iron-carbonate were identified at Columbia Hills, Gusev Crater (Morris et al., 2010; Carter and Poulet, 2012; Ruff et al., 2014). Carbonates may also be present in other environments on Mars not yet explored in situ (Ehlmann et al., 2008; Murchie et al., 2009; Michalski and Niles, 2010). To serve as a carbonate mineral endmember, a modern oolitic sand was sampled from Pigeon Cay on Cat Island, The Bahamas. Ooids are grains 0.2$2 \mathrm{~mm}$ in diameter formed of concentrically or radially laminated mineral (commonly carbonate) layers surrounding a nucleus. Ooid cortices are known to contain and preserve organic matter (O'Reilly et al., 2017).

Organic-rich shales are not expected on Mars; however, the Messel Shale from Messel, Germany, served to demonstrate the utility of the TMAH pyrolysis technique with an organic-rich endmember sample. The Messel Shale formed in an anoxic lacustrine environment in the Eocene and contains a great diversity and abundance of well-preserved organic molecules (Hayes et al., 1987; Goth et al., 1988).

\subsection{Thermochemolysis reagent tetramethylammonium hydroxide}

Wet chemistry experiments or derivatization techniques are capable of transforming polar organic molecules into more volatile forms that are detectable by GC-MS (Schummer et al., 2009) and/or freeing bound components of larger macromolecules (Grasset et al., 2002). In previous studies, TMAH thermochemolysis using pyrolysis is used to detect both free and membrane-bound fatty acids through methylation (Pulchan et al., 1997; Chefetz et al., 2000; Guignard et al., 2005; Deport et al., 2006), and transesterification of esters and methylation (Grasset et al., 2002). Through this technique, a total FAME "profile" is obtained for a given sample.

Tetramethylammonium hydroxide $(25 \%)$ in methanol (Sigma-Aldrich, P/N 334901, purity: $<10 \%$ water, $<2 \%$ chloride) is the thermochemolysis reagent used on SAM. During thermochemolysis, TMAH acts as the agent of transesterification, hydrolyzing and methylating fatty acids to generate a FAME that is more volatile and detectable by GC-MS. On SAM, in situ methylation with TMAH and a flash pyrolysis step $<600^{\circ} \mathrm{C}$ will generate FAMEs from both membrane-bound fatty acids and free fatty acids, if present, such that the total FAME profile generated includes both fatty acid categories and cannot be discriminated between based on this technique.

\subsection{Pyrolysis GC-MS conditions for analog samples}

Aliquots of each powdered sample were carried through (1) a SAM-like $35^{\circ} \mathrm{C} \min ^{-1}$ pyrolysis ramp or (2) a $500^{\circ} \mathrm{C}$ flash pyrolysis step, then GC-MS analysis to measure the distribution and abundance of FAMEs. Ground rock or sediment samples were weighed into nonreactive metal cups (sample mass was $c a$. 5-10 mg, depending on the sample). Just prior to sample analysis, TMAH in the ratio of $1 \mathrm{mg}$ sample to $1 \mu \mathrm{L}$ TMAH was added to the cup. The $n$ - $\mathrm{C}_{19: 0}$ internal standard was injected into each sample immediately 
prior to analysis to determine the reaction efficiency. The sample was then immediately loaded and dropped into the commercial Frontier 3030D pyrolyzer oven to begin the run. The hydrocarbon trap consisted of silica wool, $c a .30 \mathrm{mg}$ of Tenax TA, and a cap of silica wool within a glass inlet liner. The Tenax TA was initially conditioned at $320^{\circ} \mathrm{C}$ at a $1: 40$ split for $2 \mathrm{~h}$. Gas is directed in one direction across the inlet liner, to trap and desorb the molecules of interest for GCMS analysis. The Agilent 7890A-5975C inertXL GC-MS was equipped with a $30 \mathrm{~m}$ Restek capillary column (MXTCLP) with a $0.25 \mathrm{~mm}$ internal diameter and $0.25 \mu \mathrm{m}$ thick Crossbond $5 \%$ diphenyl $/ 95 \%$ dimethyl polysiloxane stationary phase, with $\mathrm{He}$ as the carrier gas at a $3 \mathrm{~mL} \mathrm{~min}^{-1}$ flow rate and 10:1 split. Blank (without TMAH) and "TMAH-blank" (with TMAH) cleanup analyses were run between each sample to determine and subtract the background level of residual FAMEs in the column. The mass spectrometer scanned from amu 33-550 at a rate of 2.82 scans/s. The pyrolyzer and GC programs used for benchtop optimization of these experiments are detailed in the Supplementary Materials.

\subsection{Duration of sample exposure to $T M A H$}

Time trials were performed to determine (1) whether extended sample exposure to TMAH prior to pyrolysis would degrade FAME generation and detection, and (2) the amount of time at room temperature and ambient pressure that TMAH could interact with a sample and still yield detectable FAMEs. TMAH was added to aliquots of the cryoconite sample and pyrolysis and analysis of the samples was delayed to $1,2,6,16,25,56$, and $92 \mathrm{~h}$ after TMAH was introduced. One sample set was not delayed $(0 \mathrm{~h})$ and was run immediately after TMAH introduction. Delayed samples were stored under an organically clean watch glass under ambient atmosphere in a hood. Sample analysis utilized flash pyrolysis at $500^{\circ} \mathrm{C}$ and the GC-MS program described in the Supplemental Material.

\section{5. $T M A H / M e O H$ reactions with MTBSTFA/DMF vapor}

MTBSTFA vapor is a known component within the SAM SMS, due to one or more MTBSTFA cup leaks during or after entry, descent, and landing on Mars (Glavin et al. 2013; Freissinet et al., 2015). Therefore, the effect that MTBSTFA vapor may have on TMAH thermochemolysis experiments was tested. A mixture of $0.2 \mu \mathrm{L}$ MTBSTFA in $500 \mu \mathrm{L}$ TMAH (to approximate the low concentration of MTBSTFA vapor that adsorbs to the cups in the SMS) was introduced into the py-GC-MS system with the goethite sample PS5G to identify any pyrolysis by-products.

\subsection{TMAH concentration and loss of methanol before sample pyrolysis}

In order to determine how the concentration of TMAH may be affected by the evaporation of $\mathrm{MeOH}$ from the mixture, experiments were conducted to determine the evaporation rate curve for $\mathrm{MeOH}$ at Mars-like pressures and temperatures (down to $3^{\circ} \mathrm{C}$ ), as well as SAM SMS-like temperatures (up to $50^{\circ} \mathrm{C}$ ). Aliquots ( $\mathrm{ca} .0 .5 \mathrm{~g}$ ) of TMAH in $\mathrm{MeOH}$ were weighed out and held within a Mars-like pressure range $(0.93-1.33 \mathrm{kPa})$ at $3^{\circ} \mathrm{C}, 27^{\circ} \mathrm{C}, 40^{\circ} \mathrm{C}, 45^{\circ} \mathrm{C}$, and $50^{\circ} \mathrm{C}$. A similar experiment was conducted at Mars pressures using MTBSTFA in DMF at $45^{\circ} \mathrm{C}$. The remaining masses were measured at $0,10,15,20,25,35$, and $45 \mathrm{~min}$, and assuming methanol-only evaporation (as methanol evaporates at $64.6^{\circ} \mathrm{C}$ whereas TMAH only decomposes), the amount and concentration of TMAH remaining was calculated.

\subsection{Sample peak identification}

Chromatograms and the mass spectra for FAMEs were analyzed with ChemStation software (Agilent Technologies). Identifications were based on comparison to known FAME retention times of a Supelco 37 component FAME mixture that contains saturated FAMEs, monounsaturated fatty acid methyl esters (MUFAMEs), and polyunsaturated fatty acid methyl esters (PUFAMEs) (Sigma-Aldrich). In addition, mass spectra were compared to the National Institute of Standards and Technology (NIST) Spectral Library. Quantifications were based on integration under peaks and scaled to the known amount of the $n-\mathrm{C}_{19: 0}$ internal standard unless otherwise noted.

\section{Results}

\subsection{Duration of sample exposure to $T M A H$}

The concentration of select FAMEs for the eight time trials is shown in Fig. 3. The $\mathrm{C}_{19: 0}$ internal standard concentration was highest in the 0 and $1 \mathrm{~h}$ trials but never

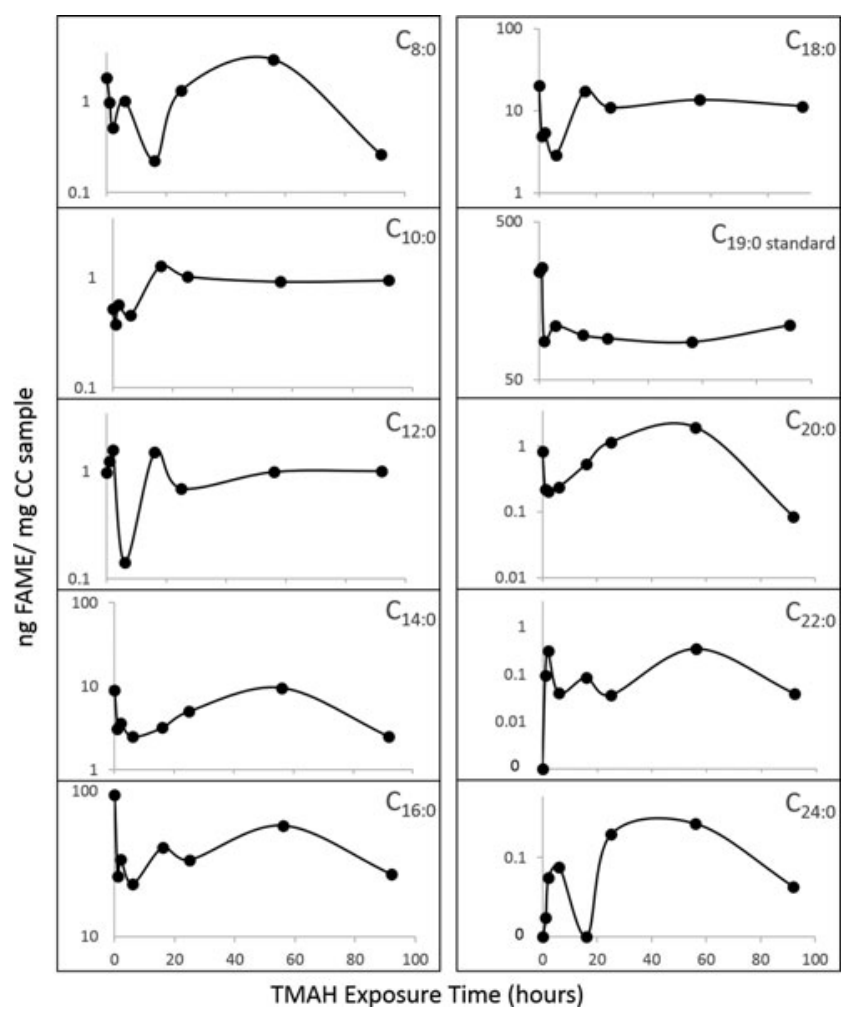

FIG. 3. Time tests for cryoconite exposure to TMAH, including instant ( $0 \mathrm{~h}$ delay), 1, 3, 6, 16, 25, 56, and $92 \mathrm{~h}$ delay before pyrolysis, for $\mathrm{C}_{8: 0}$ to $\mathrm{C}_{24: 0}$. Note the different $y$ axis scales. FAME concentrations were in general highest in the $0 \mathrm{~h}$ trial, but FAMEs were detectable up to $92 \mathrm{~h}$ after TMAH exposure and prior to pyrolysis. 
dropped below $86 \mathrm{ng} / \mathrm{mg}$ cryoconite $(\mathrm{CC})$ (66\% of maximum). The more abundant FAMEs, $\mathrm{C}_{14: 0}, \mathrm{C}_{16: 0}$, and $\mathrm{C}_{18: 0}$, were highest in the $0 \mathrm{~h}$ trials and never dropped below 2.5, 23 , and $2.9 \mathrm{ng} / \mathrm{mg} \mathrm{CC}(74 \%, 76 \%$, and $86 \%$ of maximum, respectively). The less abundant FAMEs $\left(\mathrm{C}_{8: 0}, \mathrm{C}_{10: 0}, \mathrm{C}_{12: 0}\right.$, $\mathrm{C}_{20: 0}, \mathrm{C}_{22: 0}$, and $\mathrm{C}_{24: 0}$ ) had concentrations around 0.1-1 ng/ $\mathrm{mg} \mathrm{CC}$, putting them within the range of detection, albeit at low concentrations. Of note, the lower molecular weight FAMEs that are most likely to be detected in the SAM experiment yielded sufficiently elevated concentrations to be detected even after $92 \mathrm{~h}$ of exposure. Only $\mathrm{C}_{22: 0}$ was not detected at $0 \mathrm{~h}$ exposure, and $\mathrm{C}_{24: 0}$ at 0 and $16 \mathrm{~h}$ exposure.

\section{2. $T M A H / M e O H$ reactions with MTBSTFA/DMF vapor}

The goethite sample PS5G was exposed to (1) TMAH and (2) the $0.2 \mu \mathrm{L}$ MTBSTFA in $500 \mu \mathrm{L}$ TMAH mixture. In the goethite reacted with TMAH test, the known TMAH byproduct trimethylamine (TMA) was generated, and the MTBSTFA by-product DMF was present as a carryover from the previous analysis containing MTBSTFA (Fig. 4A). The double TMA peak is likely an artifact of partial TMA solvation by $\mathrm{MeOH}$. In the goethite reacted with MTBSTFA in TMAH test, TMA and DMF were generated, as were the MTBSTFA by-products tert-butyldimethylsilanol (monosilylated water or MSW, $c a .5 .9$ and $7.4 \mathrm{~min})$ and 1,3-bis(1,1dimethylethyl)-1,1,3,3-tetramethyldisiloxane (bisilylated water or BSW, $\mathrm{ca}$. $16.7 \mathrm{~min}, \mathrm{Fig}$. 4A). The MTBSTFA by-product $\mathrm{N}$ methyl-2,2,2-trifluoroacetamide (TFMA) was not detected. As this experiment was performed with a natural goethite sample, a variety of methylated and silylated products were generated in both tests (Fig. 4B). The goethite reacted with TMAH test also generated products not shared with the mixed reagent test, for example, methylated phenanthrene and FAMEs. The goethite reacted with MTBSTFA in TMAH test generated products unique to that experiment, for example, methylated benzaldehyde, 1,2,3,4,5-pentramethyl-cyclopentadiene, 3-(1-cyclopentenyl) furan, N,N,3-trimethyl-benzenamine, phenol, and siloxanes.

\subsection{TMAH concentration and loss of methanol prior to sample pyrolysis}

Experiments were conducted to determine the evaporation rate for $\mathrm{MeOH}$ from the TMAH in $\mathrm{MeOH}$ mixture at Marslike pressures and temperatures. Results demonstrate that within $10 \mathrm{~min}$, between $9 \%\left(\right.$ at $3^{\circ} \mathrm{C}$ ) and $48 \%\left(\right.$ at $50^{\circ} \mathrm{C}$ ) of the $\mathrm{MeOH}$ in the original TMAH/MeOH mixture evaporates (Fig. 5). This changes the concentration of TMAH in the mixture after $10 \mathrm{~min}$ from $25 \%$ to $27 \%$ (at $3^{\circ} \mathrm{C}$ ) and $25 \%$ to $48 \%$ (at $50^{\circ} \mathrm{C}$ ) (Fig. 5). Results indicate that the loss of $\mathrm{MeOH}$ from the 25\% TMAH in $\mathrm{MeOH}$ mixture will be minimized at the low operating temperatures on Mars and should not significantly affect the in situ experiment based on similar benchtop experiments of $\mathrm{MeOH}$ evaporation from $\mathrm{TMAH} / \mathrm{MeOH}$ at room temperature and ambient pressure.

\subsection{Thermochemolysis and pyrolysis GC-MS analysis of analog samples}

The generation of FAMEs from a suite of Mars analog materials was tested by using both a SAM-like pyrolysis ramp and a $500^{\circ} \mathrm{C}$ flash pyrolysis (Table 3). Results are shown in Table 4, Supplementary Table S1, and Figs. 6 and 7. The $n-\mathrm{C}_{19: 0}$ internal standard was detected in all samples except those noted below.

3.4.1. Fused silica (SAM Organic Check Material analog). Small FAME peaks were detected in the fused silica sample by using both the background-subtracted SAM-like method (with 2 FAMEs $-n-\mathrm{C}_{8: 0}$ and $n$ - $\mathrm{C}_{9: 0}$-identified) and the background-subtracted $500^{\circ} \mathrm{C}$ flash pyrolysis method (with 5 FAMEs identified: $n$ - $\mathrm{C}_{8: 0}, n-\mathrm{C}_{10: 0}, n-\mathrm{C}_{12: 0}, n$ - $\mathrm{C}_{16: 0}$, and $n-\mathrm{C}_{18: 0}$ ). The effect of the background-subtraction approach is detailed in the discussion section, and all analog samples reported below represent background-subtracted analyses.

3.4.2. Cryoconite organic working sample. Eleven FAMEs and MUFAMEs were detected in the cryoconite sample treated with TMAH, while no FAMEs were detected in the cryoconite sample that did not undergo thermochemolysis with TMAH (Fig. 8). With the $500^{\circ} \mathrm{C}$ flash pyrolysis method, which used TMAH, 21 FAMEs and MUFAMEs ranging from $n-\mathrm{C}_{4: 0}$ to $n-\mathrm{C}_{25: 0}$ were detected.

3.4.3. Iron Mountain, California, iron oxyhydroxides and iron oxyhydroxysulfates. The Iron Mountain gossan sample (PS5G, $0.051 \%$ TOC) was dominated by goethite and yielded four FAMEs below $n$ - $\mathrm{C}_{11: 0}$ with the SAM-like method, and the internal standard was not detected. The flash pyrolysis method generated 7 FAMEs below $n$ - $\mathrm{C}_{20: 0}$.

The modern Iron Mountain schwertmannite precipitate (SS12, 0.97\% TOC) yielded 4 FAMEs below $n$ - $\mathrm{C}_{17: 0}$ with the SAM-like method, and the internal standard was again not detected. In contrast, the flash pyrolysis method generated 9 FAMEs or MUFAMEs with chain lengths shorter than $n$ - $\mathrm{C}_{20: 0}$.

3.4.4. Western Australia mixed iron oxides/oxyhydroxides and clay minerals. The Western Australia acidic lake core sample SSJ5 (1945 cm depth, 0.073\% TOC), which contains halite, goethite, and clay minerals, did not yield any FAMEs with the SAM-like method, and the internal standard was not detected. However, with the flash pyrolysis method, 12 FAMEs were detected below $n$ - $\mathrm{C}_{20: 0}$.

The acidic lake sediment core sample SSJ2 $(2385 \mathrm{~cm}$ depth, $0.084 \%$ TOC) does not contain an iron oxide/oxyhydroxide mineral phase but does contain halite and clay minerals, including ferruginous smectite. With the SAMlike method, 5 FAMEs below $n$ - $\mathrm{C}_{13: 0}$ were detected, and the internal standard was not detected, whereas with the flash pyrolysis method 7 FAMEs below $n-\mathrm{C}_{20: 0}$ were detected.

Lake sediment core sample SSJ3 $(3905 \mathrm{~cm}$ depth, $0.17 \%$ TOC) represents the transition from more modern acidic and saline conditions to circumneutral lake sediments of Eocene age (Bowen and Benison, 2009; Benison and Bowen, 2015) and contains halite, goethite, maghemite, and the clay minerals kaolinite, montmorillonite, and illite. The SAMlike method only yielded $n-\mathrm{C}_{14: 0}$ and $n$-C $\mathrm{C}_{18: 0}$ FAMEs, and the internal standard was not detected. The flash pyrolysis method yielded 11 FAMEs.

Eocene-age circumneutral lake sediment core sample SSJ4 ( $4350 \mathrm{~cm}$ depth, $0.81 \%$ TOC) contains, along with other mineral phases, halite, montmorillonite, and kaolinite. 

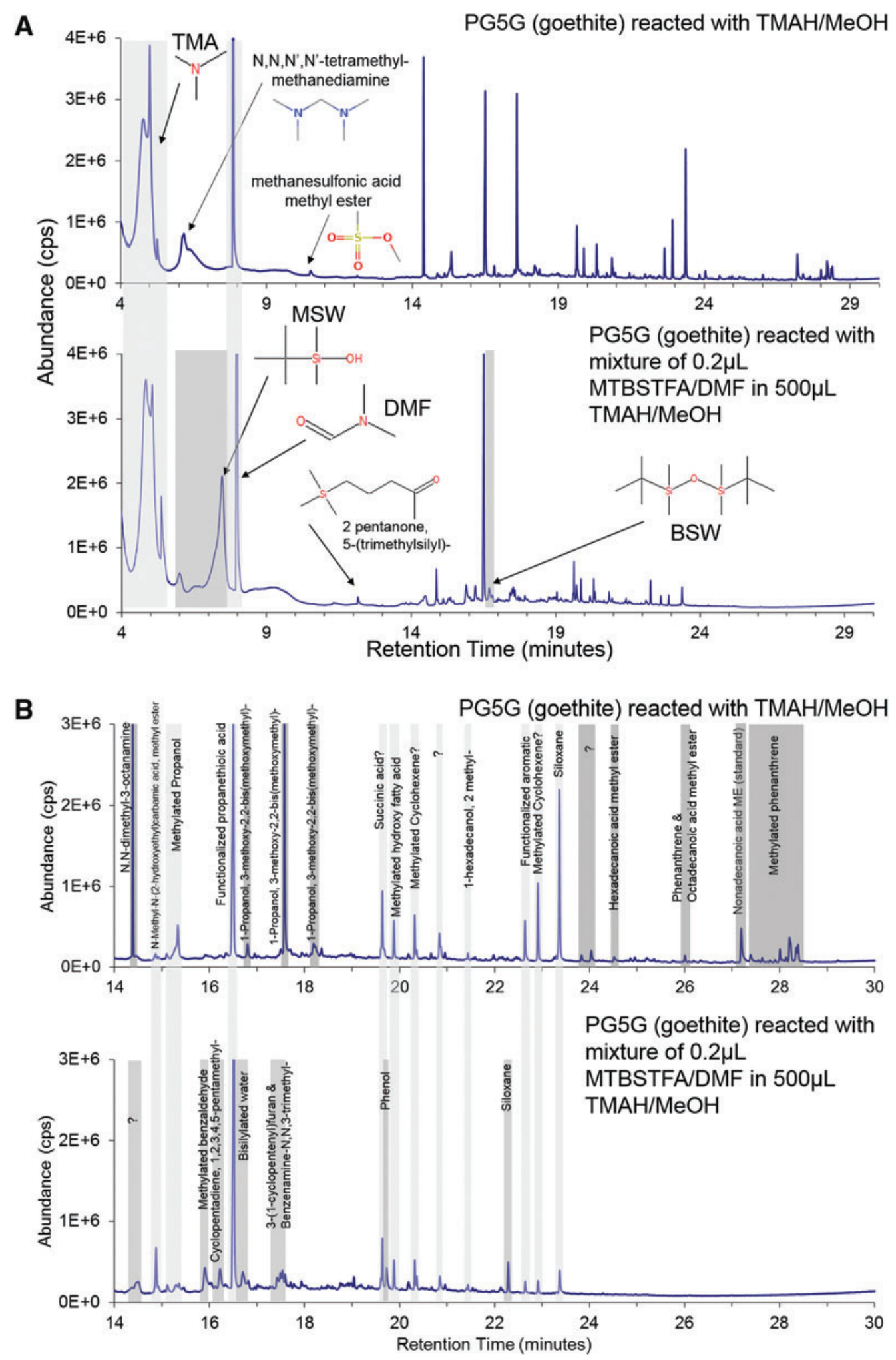

FIG. 4. (A) Total ion chromatogram of goethite sample reacted with TMAH/MeOH compared to goethite sample reacted with mixture of $0.2 \mu \mathrm{L}$ MTBSTFA/DMF in $500 \mu \mathrm{L}$ TMAH/MeOH. TMA is shared between the two tests, whereas the MTBSTFA by-products DMF, monosilylated water (MSW), and bisilylated water (BSW) are present in the mixed reagent. The DMF peak in the goethite reacted with TMAH is residual from a previous analysis. The siloxanes are a common product of column bleed. No internal standard was included in this analysis. (B) Total ion chromatogram enhancement of $\mathrm{R}_{\mathrm{t}}=14-30 \mathrm{~min}$ from (A) showing methylated and/or silylated products from the goethite sample reacted with TMAH/ $\mathrm{MeOH}$ compared to the goethite sample reacted with mixture of $0.2 \mu \mathrm{L}$ MTBSTFA/DMF in 500 $\mu \mathrm{L}$ TMAH/MeOH. Many of the same methylated compounds are detected in both experiments, with additional compounds detected separately in either experiment. Color images are available online at www.liebertpub.com/ast. 
$-\mathrm{TMAH} / \mathrm{MeOH} 3^{\circ} \mathrm{C} \rightarrow \mathrm{TMAH} / \mathrm{MeOH} 27^{\circ} \mathrm{C} \rightarrow \mathrm{TMAH} / \mathrm{MeOH} 40^{\circ} \mathrm{C} \rightarrow \mathrm{TMAH} / \mathrm{MeOH} 45^{\circ} \mathrm{C} \longrightarrow \mathrm{TMAH} / \mathrm{MeOH} 50^{\circ} \mathrm{C}-\boldsymbol{\square}-\mathrm{MTBSTFA} / \mathrm{DMF} 45^{\circ} \mathrm{C}$

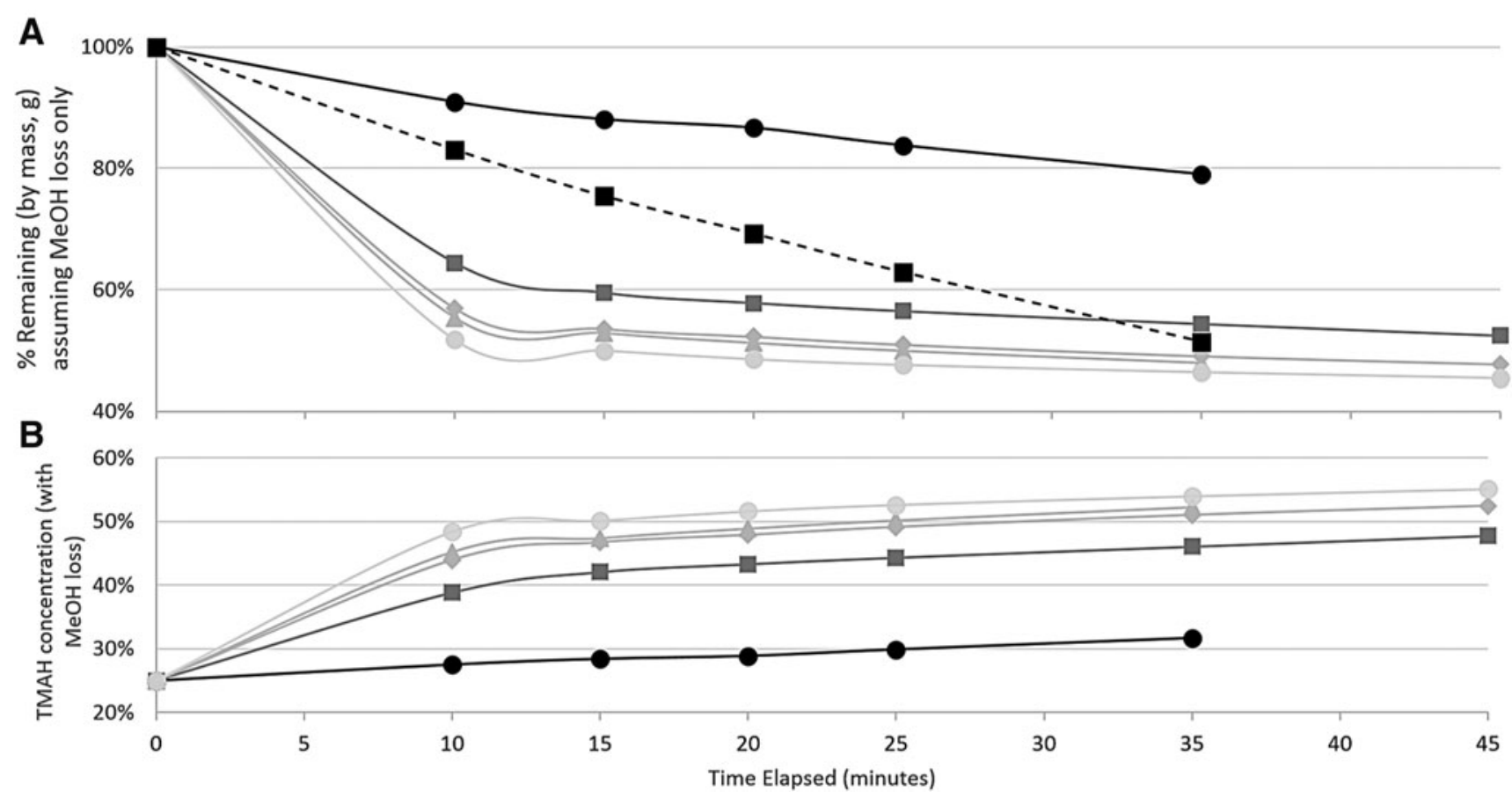

FIG. 5. (A) Percent of mass remaining after $\mathrm{MeOH}$ evaporation from TMAH/MeOH mixture at Mars-like pressure (0.93$1.33 \mathrm{kPa}$ ) and various temperatures: Mars-like: $3^{\circ} \mathrm{C}$; SAM SMS-like: $27^{\circ} \mathrm{C}, 40^{\circ} \mathrm{C}, 45^{\circ} \mathrm{C}, 50^{\circ} \mathrm{C}$. For comparison, the evaporation curve for MTBSTFA in DMF at $45^{\circ} \mathrm{C}$ is reported. (B) Percent concentration of $\mathrm{TMAH}$ in $\mathrm{TMAH} / \mathrm{MeOH}$ mixture with $\mathrm{MeOH}$ evaporation at Mars-like pressure $(0.93-1.33 \mathrm{kPa})$ and various temperatures: $\mathrm{Mars}-1$ like: $3^{\circ} \mathrm{C}$; SAM SMS-like: $27^{\circ} \mathrm{C}, 40^{\circ} \mathrm{C}, 45^{\circ} \mathrm{C}, 50^{\circ} \mathrm{C}$.

With the SAM-like method, 11 FAMEs below $n$ - $\mathrm{C}_{19: 0}$ were detected, and the internal standard was not detected, whereas 20 FAMEs below $n-\mathrm{C}_{28: 0}$ were detected with the flash pyrolysis method.

3.4.5. Iron Mountain, California, iron sulfide. The Iron Mountain pyrite sample (PS5P, 0.029\% TOC), dominated by pyrite and quartz, yielded 4 FAMEs with the SAM-like method and 4 FAMEs with the flash pyrolysis method. The $n-\mathrm{C}_{19: 0}$ internal standard was not detected using the SAMlike ramp.

3.4.6. Icelandic siliceous sinter. The inactive near-vent sinter deposit from Gunnuhver, Iceland, demonstrated a decrease in FAME detection at depth with the SAM-like method. The surface sample (IC160726.06.S, 0.024\% TOC) yielded 6 FAMEs. The subsurface sample (IC160726.06.I, $0.011 \%$ TOC) was collected at $7 \mathrm{~cm}$ depth and yielded 4 FAMEs. The flash pyrolysis method produced a similar trend, with 13 FAMEs and MUFAMEs detected in the surface sample and 11 FAMEs detected in the subsurface sample.

An active hot spring sinter deposit from Hveravellir, Iceland, demonstrated a similar decrease in FAME detection at depth with the SAM-like method. The surface sample (IC160730.09.S, 0.24\% TOC) yielded 14 FAMEs. The subsurface sample (IC160730.09.I, 0.084\% TOC) was collected at $4 \mathrm{~cm}$ depth and yielded 11 FAMEs. The flash pyrolysis method produced a similar trend, with 17 FAMEs,
MUFAMEs, and PUFAMEs detected in the surface sample and 10 FAMEs detected in the subsurface sample.

3.4.7. Bahamian carbonates. The modern carbonate ooid sample (CIMO, ca. 2.1\% TOC) yielded 5 FAMEs with the SAM-like method and 17 FAMEs with the flash pyrolysis method.

3.4.8. Organic-rich shale. Using the SAM-like method, the Messel shale sample (MES, 33\% TOC) yielded 23 FAMEs and MUFAMEs, and with the flash pyrolysis method 42 FAMEs and MUFAMEs were detected.

\section{Discussion}

\subsection{Benchtop and SAM flight thermochemolysis optimization}

To optimize the TMAH thermochemolysis benchtop experiment, several operational variables were evaluated, including duration of sample exposure to TMAH, TMAH reactions with MTBSTFA, and evaporation of methanol from the TMAH solution. The sample exposure to TMAH tests suggest that the sample should be run as soon as possible after exposure to TMAH, but the sample integrity should not be compromised if the pyrolysis and analysis are delayed up to $92 \mathrm{~h}$ after sample exposure to TMAH (Fig. 3). The presence of MTBSTFA vapor will not significantly affect the TMAH experiment and expected methylated products. The loss of methanol from the TMAH/MeOH 


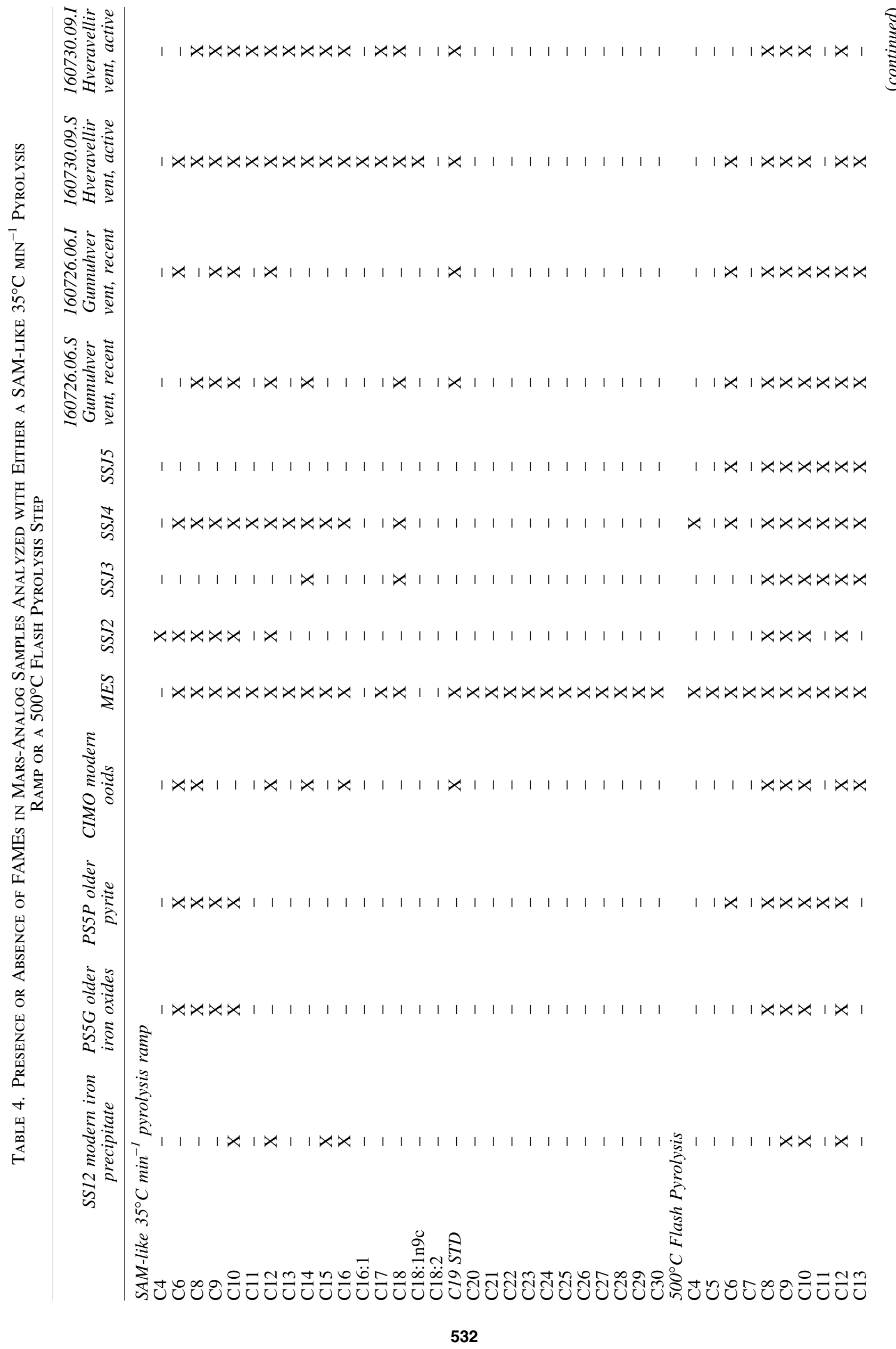




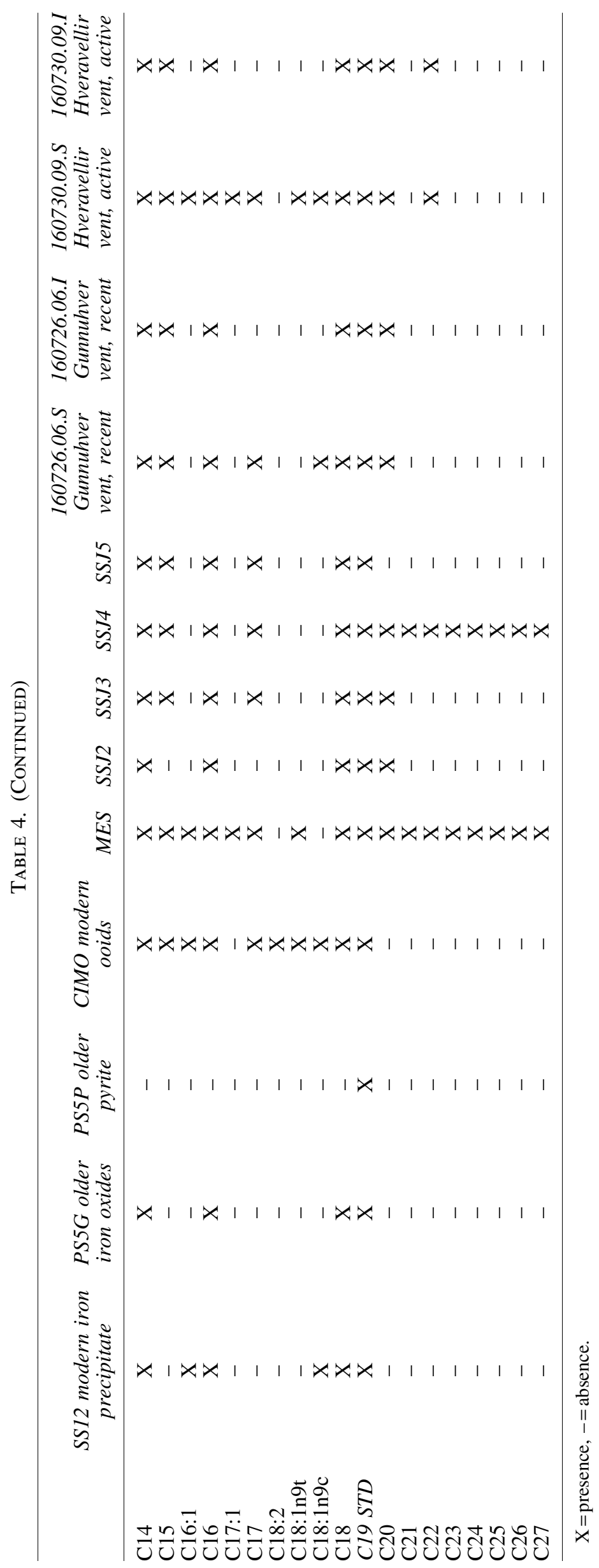




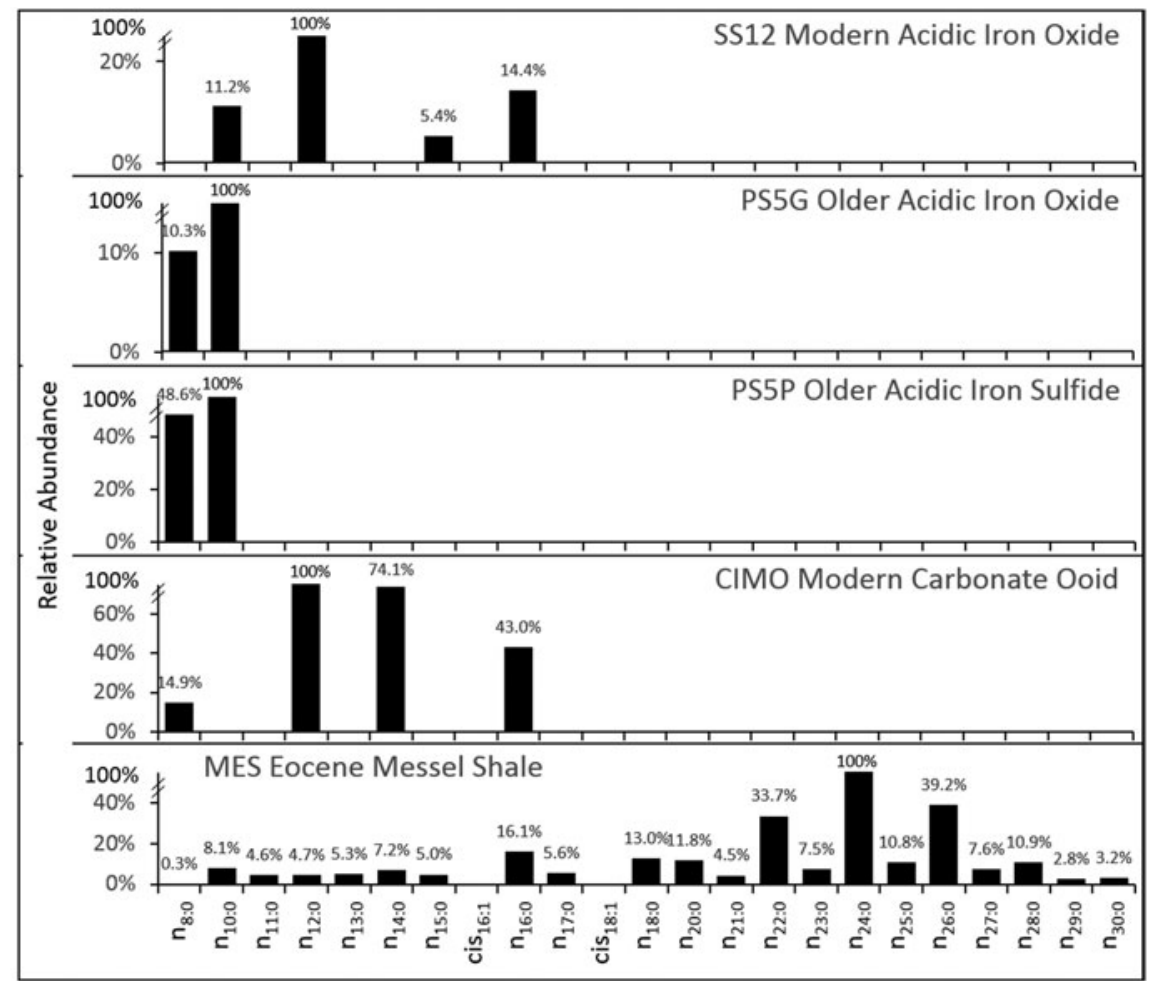

B

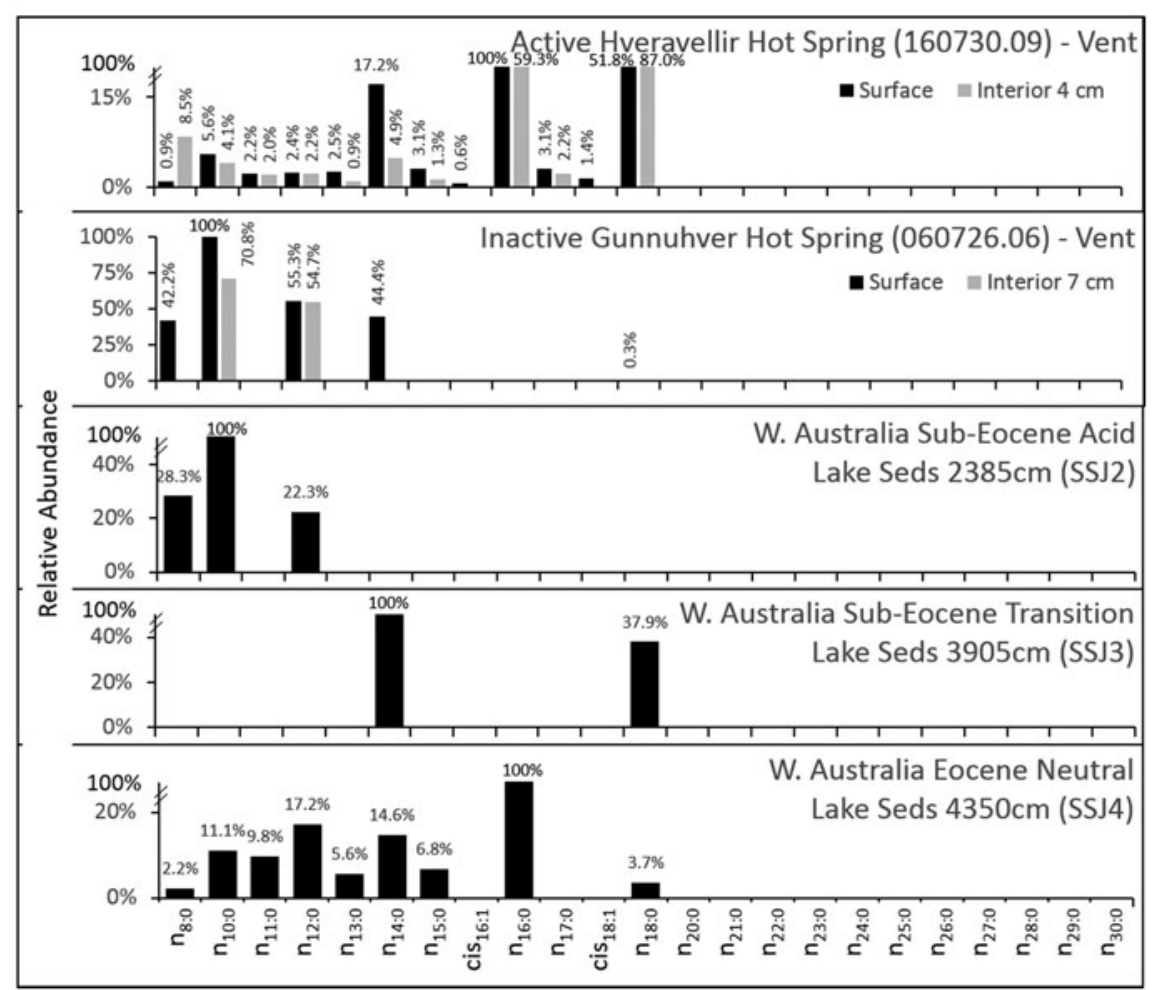

FIG. 6. (A) Percent relative abundance of FAME profiles for the mineral classes analyzed with a SAM-like $35^{\circ} \mathrm{C} \mathrm{min}{ }^{-1}$ pyrolysis ramp. The modern acidic iron oxide was dominated by $n$ - $\mathrm{C}_{10: 0}, n-\mathrm{C}_{12: 0}, n-\mathrm{C}_{15: 0}$, and $n-\mathrm{C}_{16: 0}$ FAMEs. The older iron oxide and iron sulfides contained only $n$ - $\mathrm{C}_{8: 0}$ and $n$-C $\mathrm{C}_{10: 0}$ FAMEs. The modern carbonate ooid was dominated by $n$ $\mathrm{C}_{12: 0}, n-\mathrm{C}_{14: 0}$, and $n$ - $\mathrm{C}_{16: 0}$ FAMEs. The Eocene Messel Shale contained a great diversity of FAMEs and was dominated by $n-\mathrm{C}_{24: 0}$ and other long chain length FAMEs up to $n-\mathrm{C}_{30: 0}$. As the $\mathrm{C}_{19: 0}$ internal standard was not detected in all ramped pyrolysis analyses, abundance in each profile is normalized to the highest FAME cps detection from that sample. (B) Percent relative abundance of FAME profiles for the mineral classes analyzed with a SAM-like $35^{\circ} \mathrm{C} \mathrm{min}{ }^{-1}$ pyrolysis ramp (continued). The active Icelandic hot spring was dominated by $n-\mathrm{C}_{16: 0}$ and $n-\mathrm{C}_{18: 0}$ FAMEs in the surface and interior samples and contained several shorter-length FAMEs. The recently active hot spring was dominated by $n-\mathrm{C}_{10: 0}$ in the surface and interior samples. The acidic sub-Eocene lake sediment (SSJ2) was dominated by $n$ - $\mathrm{C}_{10: 0}$, and the circumneutral Eocene lake sediment (SSJ4) was dominated by $n$-C $\mathrm{C}_{16: 0}$. As the $\mathrm{C}_{19: 0}$ internal standard was not detected in all ramped pyrolysis analyses, abundance in each profile is normalized to the highest FAME cps detection from that sample. 
A

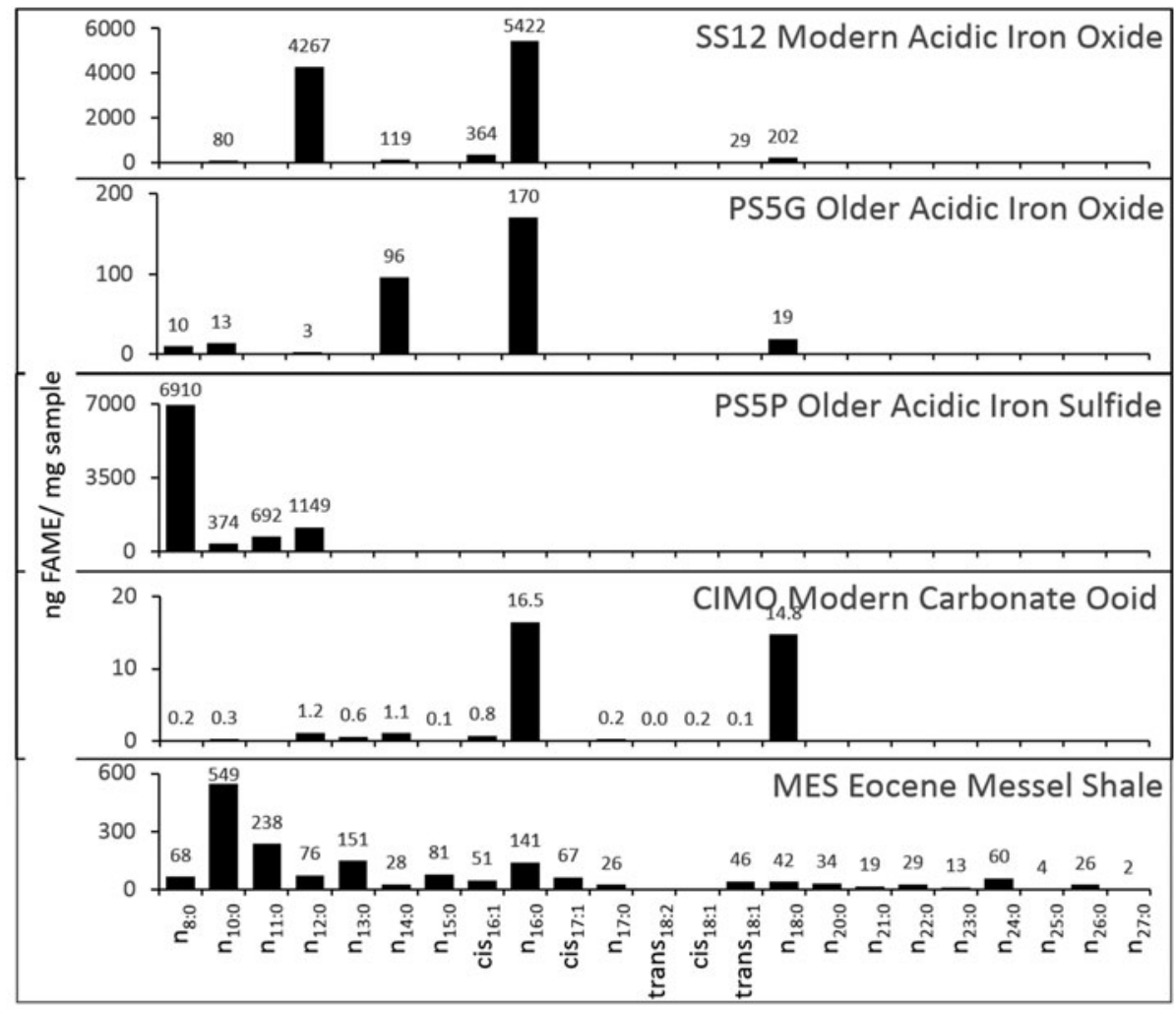

B

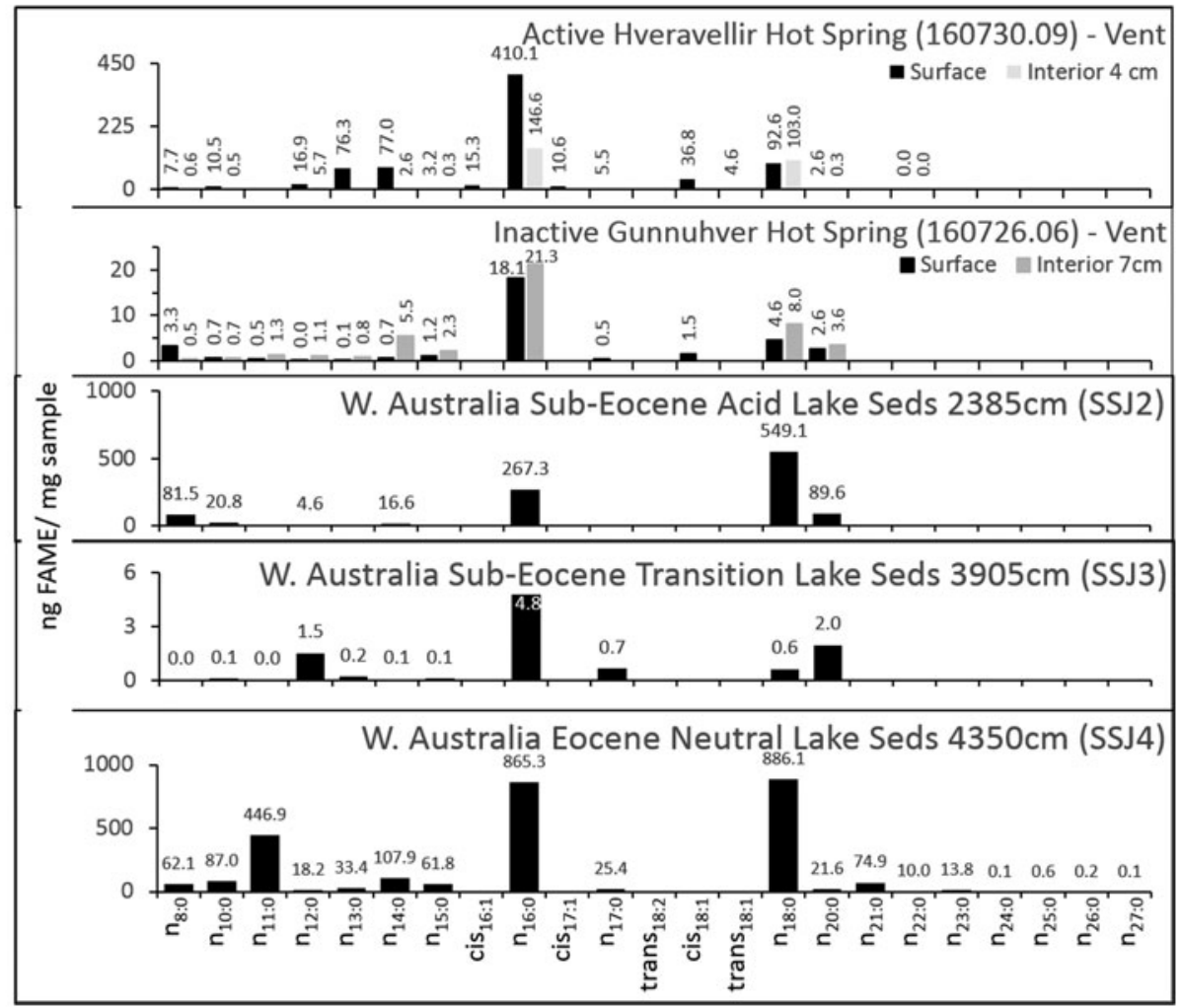

FIG. 7. (A) FAME profiles for the mineral classes analyzed with the $500^{\circ} \mathrm{C}$ flash pyrolysis method. FAMEs are quantified as ng FAME/mg sample. Most samples are dominated by $n-\mathrm{C}_{16: 0}$ and $n$-C $\mathrm{C}_{18: 0}$. The SS12 sample contains a modern microbial community and had a very high concentration of FAMEs/mg sample relative to older samples or those in which the microbial communities had been entombed by minerals. The high FAME concentration in the PS5P sample indicates a modern microbial community within the older sample. The even-over-odd carbon number preference is apparent in the FAMEs $>n-\mathrm{C}_{18: 0}$ from the Messel Shale. (B) FAME profiles for the mineral classes analyzed with the $500^{\circ} \mathrm{C}$ flash pyrolysis method (continued). Most samples are dominated by $n-\mathrm{C}_{16: 0}$ and $n-\mathrm{C}_{18: 0}$. The active Icelandic hot spring contained a higher FAME concentration than the inactive hot spring system. An odd-over-even carbon number preference is observed in the FAMEs $>n$ - $\mathrm{C}_{18: 0}$ from the Western Australia neutral lake sediments, which also contain the highest concentration of FAMEs of the Western Australia samples. 


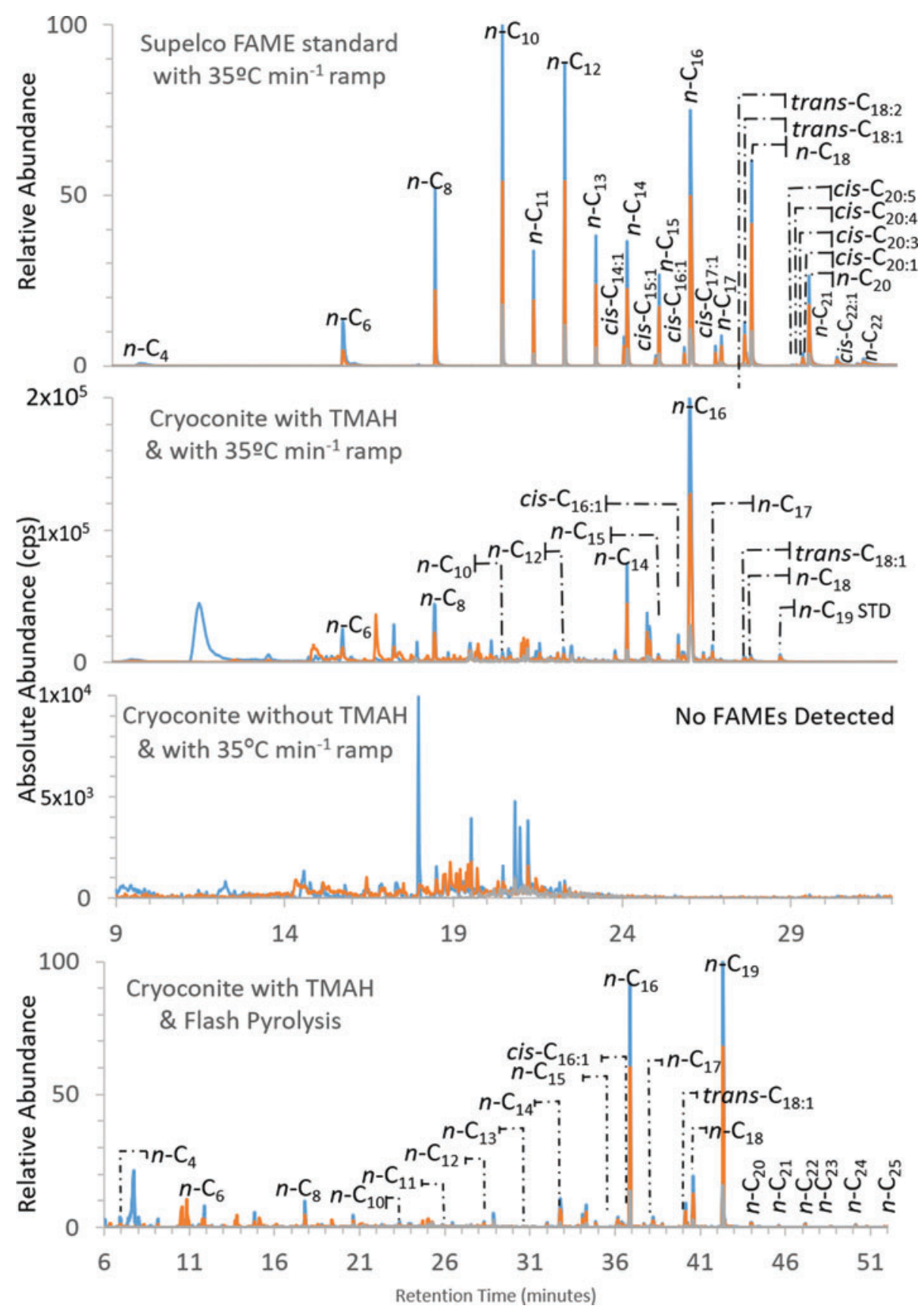

FIG. 8. Selected ion chromatogram of Supelco FAME 37 standard and cryoconite analyzed by py-GC-MS. The FAME standard was used to confirm FAME retention times in the cryoconite sample treated with and without TMAH. The sample not reacted with TMAH did not yield detectable FAMEs but did contain molecules such as trimethylsilyl cyanide, furfural, methylated furancarboxaldehyde, and siloxanes. The TMAH-reacted cryoconite analyzed by flash pyrolysis is included to demonstrate that flash pyrolysis yields more FAMEs than the ramped pyrolysis method. The $35^{\circ} \mathrm{C} \mathrm{min}{ }^{-1}$ and $500^{\circ} \mathrm{C} \mathrm{flash}$ pyrolysis methods and GC programs are described in the Supplementary Materials. FAMEs identified by retention time and $m / z=74,87,143$. Blue lines $=m / z, 74$, orange lines $=m / z, 87$, gray lines $=m / z, 143$. Color images are available online.

mixture at Mars temperatures will not significantly impact the experiment. The operating parameters described above will continue to be optimized for the SAM flight instrument. Further investigation will be conducted to optimize the flight experiment, including determining the exact percentage of sample-reacted TMAH to be vented from SAM versus sent to the GC-MS. Continued testing of the TMAH thermochemolysis experiment under Mars temperature and pres- sure conditions is planned for the SAM testbed, a highfidelity replica of the SAM flight instrument housed at NASA Goddard Space Flight Center.

\subsection{Thermochemolysis of analog samples}

FAME generation via TMAH thermochemolysis in mineralogically variable Mars-analog samples was tested with 
Table 5. Fatty Acid Biomarkers Detectable with TMAH Thermochemolysis, Abbreviations, and Possible Biogenic Sources of Fatty Acids (Modified from O’Reilly et aL., 2017)

\begin{tabular}{|c|c|c|}
\hline Name & Abbreviation & Source and Interpretation \\
\hline Straight-chain saturated fatty acids ( $<20$ carbons) & $\mathrm{C}_{14: 0}$ to $\mathrm{C}_{18: 0}$ & Bacteria, eukaryotes $^{\mathrm{a}}$ \\
\hline Long-straight-chain saturated fatty acids & $\mathrm{C}_{20: 0}$ to $\mathrm{C}_{30: 0}$ & $\begin{array}{l}\text { Microalgae or terrestrial plants, } \\
\text { Early diagenetic selective preservation }\end{array}$ \\
\hline Hexadec-9-enoic acid & $\mathrm{C}_{16: 1 \omega 7}$ & Diatoms, $_{\text {proteobacteria }}{ }^{\mathrm{e}}$ \\
\hline Hexadec-11-enoic acid & $\mathrm{C}_{16: 1 \omega 5}$ & Bacteria, possibly sulfate-reducing bacteria ${ }^{f}$ \\
\hline Octadec-11-enoic acid & $\mathrm{C}_{18: 1 \omega 7}$ & Bacteria, microalgae ${ }^{\mathrm{e}}$ \\
\hline Octadec-9-enoic acid & $\mathrm{C}_{18: 1 \omega 9}$ & Eukaryotes $^{\mathrm{a}}$ \\
\hline Octadecadienoic acid & $\mathrm{C}_{18: 2 \omega 6}$ & Possibly cyanobacteria, fungi ${ }^{\mathrm{g}, \mathrm{h}}$ \\
\hline Loss of unsaturated fatty acids & & Bacterial heterotrophy/early diagenesis ${ }^{\mathrm{h}}$ \\
\hline
\end{tabular}

${ }^{\mathrm{a}}$ Volkman, 2006; ${ }^{\mathrm{b}}$ Volkman et al., 1989; ${ }^{\mathrm{c}}$ Wilhelm et al., 2017; ${ }^{\mathrm{d}}$ Haddad et al., 1992; ${ }^{\mathrm{e}}$ Volkman et al., $1998 ;{ }^{\mathrm{f}}$ Elvert et al., $2003 ;{ }^{\mathrm{g}} \mathrm{Kelly}$

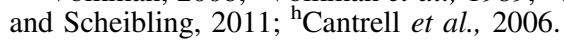

both a SAM-like $\left(35^{\circ} \mathrm{C} \mathrm{min}^{-1}\right)$ pyrolysis step and a $500^{\circ} \mathrm{C}$ flash pyrolysis step. In general, the flash pyrolysis method yielded a greater number and diversity of FAMEs from all samples than the SAM-like pyrolysis ramp method (Table 4). Common sources for the FAMEs identified are presented in Table 5 and interpreted below in the context of the sample environment. The FAME profiles generated with SAM-like pyrolysis are shown in Fig. 6, and those generated with flash pyrolysis are shown in Fig. 7, to demonstrate the distinct profile "fingerprints" of each mineralogy class.

4.2.1. Fused silica (Curiosity rover Organic Check Material analog). Given that this sample was combusted at $550^{\circ} \mathrm{C}$ for $8 \mathrm{~h}$ prior to analysis, and several TMAH-blanks were run before sample analysis, carryover contamination from previously run samples is the likely source of the very small FAME peaks detected. Evidence for this is discussed in detail in Section 4.2.10.

4.2.2. Cryoconite organic working sample. The results from the SAM-like pyrolysis of the cryoconite sample with and without TMAH, and the $500^{\circ} \mathrm{C}$ flash pyrolysis with TMAH experiment, are shown in Fig. 8 and compared to the Supelco 37 FAME standard. These results are consistent with the expectation that TMAH will generate methylated fatty acids from ester-linked lipids, whereas samples not treated with TMAH will not yield FAMEs. The $500^{\circ} \mathrm{C}$ flash pyrolysis experiments yielded more FAMEs than the SAMlike ramp; this is described in more detail in Section 4.2.11.

4.2.3. Iron Mountain iron oxyhydroxides and iron oxyhydroxysulfates. The straight-chain saturated FAMEs detected in the modern Iron Mountain precipitate (SS12) may be indicative of both bacterial and eukaryotic cell membranes (Volkman, 2006). The cis- $\mathrm{C}_{16: 1}$ may indicate the presence of diatoms (which were identified via SEM in this sample) or proteobacteria (Volkman et al., 1998), or possibly sulfate-reducing bacteria (Elvert et al., 2003), although sulfate-reducing bacteria have not yet been identified in the modern pipe precipitate. The cis- $\mathrm{C}_{18: 1}$ can indicate the presence of bacteria or microalgae (Volkman et al., 1998) or eukaryotes (Volkman, 2006), depending on the location of the unsaturation.

Assuming unsaturated FAMEs were initially present in the older Iron Mountain gossan sample (PS5G) as they are in the modern sample, loss of those unsaturated FAMEs can indicate the effects of diagenesis or bacterial heterotrophy (Sun et al., 1997). The low FAME detection in this sample may be due to a decreased initial microbial population within the gossan rock or a reduction in FAME preservation due to the presence of iron oxides/oxyhydroxides (Sumner, 2004).

4.2.4. Western Australia mixed iron oxides/oxyhydroxides and clays. The Western Australia lake sediment core samples ranged from acidic at $1945 \mathrm{~cm}$ depth to circumneutral at $4350 \mathrm{~cm}$ depth. Several of these samples contained a mixture of iron oxide/oxyhydroxide and clay minerals, but environmental $\mathrm{pH}$ demonstrated the strongest influence on the preservation of fatty acids in these sediments. With both pyGC-MS methods, fewer FAMEs and lower FAME concentrations were detected in the acidic sediment samples relative to the circumneutral sediment samples, confirming the thermodynamic assumption that organics are more rapidly degraded in acidic rather than circumneutral environments. However, the resilience of the remaining FAMEs in these Eocene to sub-Eocene age samples suggests that the mixture of iron oxides/oxyhydroxides and clay minerals preserves organics better than iron oxides/oxyhydroxides alone (e.g. in the PS5G goethite sample).

The long straight-chain saturated FAMEs $\left(n-\mathrm{C}_{20: 0}\right.$ to $n$ $\mathrm{C}_{28: 0}$ ) detected in SSJ4 can be indicative of microalgae (Volkman et al., 1989), terrigenous plant origins, or early diagenetic selective preservation (Haddad et al., 1992). The long-chain FAMEs identified in this sample exhibit a strong odd-over-even carbon number preference, which is consistent with a terrigenous origin likely in the form of cuticular waxes (Eglinton and Hamilton, 1967), and are consistent with previous results using the Bligh and Dyer (1959) method, a standard laboratory protocol used for lipid extractions (Johnson et al., manuscript submitted for publication).

4.2.5. Iron Mountain, California, iron sulfide. The PS5P pyrite sample presented unique results and challenges in these experiments. The sample is almost completely composed of pyrite $\left(\mathrm{FeS}_{2}\right)$, with very little quartz present. Only 6 FAMEs below $n-\mathrm{C}_{13: 0}$ were detected when using either of the pyrolysis methods, and the $n-\mathrm{C}_{19: 0}$ internal standard was either not present (in $35^{\circ} \mathrm{C} \mathrm{min}^{-1}$ pyrolysis ramp) or present at a very low concentration (in $500^{\circ} \mathrm{C}$ flash pyrolysis). 
FAMEs may not have been well generated and transferred to the column due to the majority of pyrite decomposition beginning over $446^{\circ} \mathrm{C}$ (Yani and Zhang, 2010), which was not met with the SAM-like pyrolysis used here and was only exceeded with the $500^{\circ} \mathrm{C}$ flash pyrolysis method. Any organics bound within the pyrite may have just begun to be released during pyrite decomposition and so were not fully methylated prior to transfer to the column. For comparison, the $\mathrm{Fe}(\mathrm{III})$ oxide mineral goethite decomposes between $290^{\circ} \mathrm{C}$ and $330^{\circ} \mathrm{C}$ (Govaert et al., 1976; Földvári, 2011), liberating putative macromolecules for reaction with TMAH at the temperatures achieved with the SAM-like and flash pyrolysis methods. Future benchtop and flight experiments should therefore consider mineral decomposition temperatures prior to establishing a maximum pyrolysis temperature.

4.2.6. Icelandic siliceous sinter. The inactive near-vent sinter deposit at Gunnuhver demonstrated a decrease in FAME detection at depth with both the SAM-like method (from 6 to 4 FAMEs detected) and the flash pyrolysis method (from 13 to 11 FAMEs detected). With the SAMlike method, the $n-\mathrm{C}_{8: 0}, n-\mathrm{C}_{14: 0}$, and $n-\mathrm{C}_{18: 0}$ FAMEs were lacking in the subsurface relative to the surface samples, indicating FAME degradation in the subsurface. With the flash pyrolysis method, the $n-\mathrm{C}_{17: 0}$ and $\mathrm{cis}-\mathrm{C}_{18: 1}$ FAMEs were not detected in the subsurface sample, which may indicate some early diagenetic processing of the sinter which will decrease the concentration of preserved MUFAMEs.

The active vent deposit at Hveravellir demonstrated a similar decrease in FAME detection at depth with both the SAMlike method (from 14 to 11 FAMEs detected) and the flash pyrolysis method (from 17 to 10 FAMEs detected). In the SAM-like method, the $n-\mathrm{C}_{6: 0}$, cis- $\mathrm{C}_{16: 1}$, and cis- $\mathrm{C}_{18: 1}$ FAMEs were lacking in the subsurface relative to the surface samples. The flash pyrolysis method yielded the cis- $\mathrm{C}_{16: 1}, n-\mathrm{C}_{17}$, cis$\mathrm{C}_{17: 1}$, cis- $\mathrm{C}_{18: 1}$, and $\mathrm{C}_{18: 2}$ FAMEs in the surface sample (cis versus trans in the $\mathrm{C}_{18: 2}$ PUFAME could not be resolved based on retention time of comparable PUFAMEs in the Supelco FAME standard). The presence of $\mathrm{C}_{18: 2}$ can be indicative of cyanobacterial communities (Kelly and Scheibling, 2012) or fungi (Cantrell et al., 2006) and is a reasonable expectation for a surface-exposed hot spring environment. In the flash pyrolysis method, the $n-\mathrm{C}_{6: 0}, n-\mathrm{C}_{13: 0}, c i s-\mathrm{C}_{16: 1}, n-\mathrm{C}_{17: 0}, c i s-\mathrm{C}_{17: 1}$, cis- $\mathrm{C}_{18: 1}$, and $\mathrm{C}_{18: 2}$ FAMEs were not detected in the subsurface sample, again indicative of some early diagenetic processing of the sinter. The $n-\mathrm{C}_{20: 0}$ and $n-\mathrm{C}_{22: 0}$ FAMEs, indicative of algae or terrestrial plants (O'Reilly et al., 2017), were also detected in both Heravellir vent samples by using the flash pyrolysis method.

4.2.7. Bahamian carbonates. Both the SAM-like pyrolysis and flash pyrolysis of the modern carbonate ooid sample yielded FAME results that represent a small fraction of the lipids present in these ooids (O'Reilly et al., 2017). Using an off-line solvent extraction technique, O'Reilly et al. (2017) identified monocarboxylic fatty acids as the major lipid class, followed by methyl-branched and $\beta$ hydroxy fatty acids, dicarboxylic acids, hopanoic acids, monoethers, alkanes, hopanes, and steranes as carbonatebound lipids in these modern Bahamian ooids.

Sample CIMO contained 5 detectable FAMEs below $n$ $\mathrm{C}_{17: 0}$, and these results exclusively represented even carbon number FAMEs. The flash pyrolysis method yielded 17 FAMEs ranging from $n-\mathrm{C}_{8: 0}$ to $n-\mathrm{C}_{22: 0}$, including the MUFAMEs cis- $\mathrm{C}_{14: 1}$, cis- $\mathrm{C}_{16: 1}$, and cis- $\mathrm{C}_{18: 1}$. The even-over-odd carbon number preference of FAMEs $<\mathrm{C}_{20: 0}$ indicates contributions from a modern microbial community. Although the MUFAMEs were a very minor component of the bound FAME pool in the ooid grains, they were far more abundant in the biofilm attached to the surface of the ooid grains (O'Reilly et al., 2017), and the MUFAME signal detected here is likely from the surface biofilm algae and bacteria.

4.2.8. Organic-rich shale. The even-over-odd carbon number preference of FAMEs $>\mathrm{C}_{18: 0}$ in sample MES is consistent with microbial alteration of algal detritus within the Messel Shale (Elias et al., 1997). Long straight-chain fatty acids are most consistent with terrestrial plant $\left(\mathrm{C}_{24}\right.$ to $\mathrm{C}_{34}$ ) and algal origins $\left(\mathrm{C}_{20}\right.$ to $\left.\mathrm{C}_{24}\right)$ (O'Reilly et al., 2017), and the lipids in the Messel Shale have a demonstrated algal origin (Goth et al., 1988).

4.2.9. $n-\mathrm{C}_{19: 0}$ internal standard anomaly. The $n-\mathrm{C}_{19: 0}$ internal standard was injected into each sample immediately prior to analysis to determine the reaction efficiency and was successfully detected in all SAM-like pyrolysis analyses with the notable exception of the iron-bearing samples. Comparably longer-chain FAMEs, such as $n$-C $\mathrm{C}_{18: 0}$, are detected in select iron-bearing samples (SSJ3 and SSJ4), but FAME detection in most iron-bearing samples ended at $n$ $\mathrm{C}_{16: 0}$ or shorter chains. It is possible in these cases that the long-chain FAMEs, including $n-\mathrm{C}_{19: 0}$, are breaking down in the pyrolysis oven. In comparison, when subjected to the $500^{\circ} \mathrm{C}$ flash pyrolysis method, the $n-\mathrm{C}_{19: 0}$ FAME was detected in all samples, with the peak in the PS5P pyrite sample being extremely small.

SAM-like pyrolysis of both the pyrite and the acidic Fe(III)bearing samples did not yield long-chain FAMEs. However, SAM-like pyrolysis of the circumneutral Fe(III)-bearing samples did yield long-chain FAMEs. It appears that the samples formed in acidic environments may be undergoing a reaction with the strongly alkaline TMAH in the pyrolysis oven. This and/or some other synergistic processes could be retaining or destroying the long-chain FAMEs in these samples at slow SAM-like pyrolysis ramps. The results suggest a link between the loss of long-chain FAMEs, the presence of iron minerals formed in acidic environments, and the $35^{\circ} \mathrm{C} \mathrm{min}{ }^{-1} \mathrm{SAM}-$ like ramp, but a clear mechanism for the loss of the long-chain FAMEs is not yet elucidated.

4.2.10. Comparison of background ("TMAH blank") to sample signal. The identification of FAMEs in this work was done in part by performing a "TMAH blank" run before each sample analysis. As with the samples, a cup with $4 \mu \mathrm{L}$ of TMAH was analyzed through the full pyrolysis and GC-MS programs to determine the background level of FAME contamination and possible carryover from previous samples. Each "TMAH blank" spectrum was subtracted from the subsequent sample spectrum to remove any potential carryover signal. No data is reported in which the background ("TMAH blank") spectrum was higher than the sample spectrum, with the assumption being that the sample signal was not elevated enough to be confidently identifed above background levels. 
To quantify differences between the two spectra for each FAME peak, the percentage that the background spectrum represents relative to the signal spectrum was calculated. Although all data presented in Table 4 represent signal elevated above background, the calculation in Supplementary Table S2 serves as an indicator that the signal is either greatly elevated above background ( $0 \%$ of the background is included in the signal) or is very similar to background (up to $100 \%$ of the background is included in the signal). Therefore, lower percentages represent a greater signal-tonoise ratio and indicate more confidence that the FAME peak identified is native to the sample.

In general, the saturated FAME, MUFAME, and PUFAME signal in most samples was greatly elevated over background values (as indicated in Supplementary Table S2 with values closer to $0 \%$ ). In some cases, the background/sample signal ratio varied greatly (e.g., flash pyrolysis PS5G and CC). In these situations, most FAME peaks were greatly elevated above background, with one or a few FAME peak values (mostly the very low or high molecular weight FAMEs) being more similar to the background levels. Samples OCM and PS5P in particular exhibit sample signal values that were quite similar to background values. As the instrument background was always carefully lowered before each run with a series of high-temperature bake-out sequences, blank analyses, and "TMAH blank" flushes, these results indicate that FAME signals in these two samples are very low and are most likely comparable with instrument background.

4.2.11. Comparison of $500^{\circ} \mathrm{C}$ flash pyrolysis and $35^{\circ} \mathrm{C} \mathrm{min}{ }^{-1}$ ramp pyrolysis methods. The SAM-like pyrolysis employs a $35^{\circ} \mathrm{C} \mathrm{m^{-1 }}$ ramp to $400^{\circ} \mathrm{C}$, which took $\mathrm{ca}$. $10 \mathrm{~min}$ to reach maximum temperature, while the flash pyrolysis method used an instantaneous $500^{\circ} \mathrm{C}$ flash pyrolysis step held for 1 min. Samples treated with the flash pyrolysis step almost always yielded a greater number and diversity of FAMEs than the SAM-like $35^{\circ} \mathrm{C} \min ^{-1}$ ramp method. This was likely due to several factors: the gradual ramp at $35^{\circ} \mathrm{C} \mathrm{min}$ generates radicals, and the temperature ramp may limit the optimal time for reaction of TMAH with the solid sample. The flash pyrolysis step is likely more efficient in reacting TMAH with macromolecules in the solid sample and transferring the eluent to the column. The flash pyrolysis step generated water, which may serve as a carrier for the eluent and facilitate more efficient transfer to the column. In addition, in flash pyrolysis the sample molecules are released simultaneously to the TMAH as it is vaporized, as opposed to in ramp pyrolysis in which some of the TMAH may have been lost by the time the sample reaches temperatures at which the minerals will degrade and release organics, or temperatures at which the organics vaporize. These factors in concert may limit the number and diversity of FAMEs produced with a $35^{\circ} \mathrm{C} \mathrm{min}^{-1}$ pyrolysis ramp.

4.2.12. Biotic and abiotic hydrocarbon generation and implications for fatty acid detection. The capability of SAM to detect short, medium, and long-chain FAMEs and determine any carbon number preference is critical for determining the provinance of fatty acids on Mars. Biotically generated fatty acids may have characteristic branching or unsaturations that can be used to identify the organism (or organisms) that generated the fatty acid (see Table 5). An even-over-odd carbon number preference is often correlated as a product of bacteria and other microbes in recent to Miocene-aged sediments (Nishimura and Baker, 1986; Grimalt and Albaiges, 1987) and may indicate the presence of a recent microbial community. Depending on the environment, this even-over-odd preference can reflect reductive processes altering lipid compounds, or microbial alteration of algal detritus on Earth (Elias et al., 1997).

In contrast, some aliphatic and aromatic hydrocarbons may be generated abiotically. One such pathway enlists Fischer-Tropsch-type reactions, in which iron from a meteoric source serves as the catalyst to generate lipids from carbon monoxide and hydrogen (Gelpi et al., 1970). In these senarios, saturated and unsaturated hydrocarbons may be generated that range from $n-\mathrm{C}_{2: 0}$ to $>n-\mathrm{C}_{35: 0}$, but with no carbon number preference (e.g., the carbon number preference index = 1.0 [Bray and Evans, 1961; Gelpi et al., 1970; McCollom et al., 1999]). Interplanetary dust particles or cometary infall may undergo these reactions on Mars to generate a steady signal of aliphatic hydrocarbons that are detectable with the SAM TMAH experiment.

It is important to note that the carbon chain length and carbon number preference are not always diagnostic of biotic versus abiotic genesis. Short-chain carboxylic acids may represent metabolic products not incorporated into membranes, and as discussed above, Fischer-Tropsch-type reactions can generate long-chain carboxylic acids. A carbon number preference may be more diagnostic of abiotic versus biotic processes, but the even-over-odd or odd-overeven preference may differ from trends observed on Earth. The even-over-odd expression in lipid chains, a result of enzymatic biochemistry, reflects monomer addition of a 2-C subunit. In contrast, isoprenoid lipids are built by 5-C isoprene subunits. It is the addition of subunits by the enzymatic activity of organisms that is associated with the lipid carbon number preference biosignature (Summons et al., 2008; Georgiou and Deamer, 2014), and it is possible that extraterrestrial life, if present, may build lipid structures of 2-C, 3-C, 4-C, 5-C, and so on, subunits. Therefore, studies such as the one presented here are vital to further resolving the abiotic versus biotic genesis of fatty acids detected with the in situ TMAH experiment.

Lastly, the presence of perchlorates on Mars may dramatically affect the preservation and detection of any organics. The Viking life-detection experiments were intially interpreted to show a dearth of native organics (Biemann et al., 1976, 1977). These results have recently been reinterpreted to reveal that the detected organics chloromethane and dichloromethane are the result of martian organics reacting with perchlorates during heating (NavarroGonzález et al., 2010; Guzman et al., 2018). Similar concerns exist for analyzing samples with the GC-MS on SAM-chloromethane and chlorobenzene have been detected with SAM with the source attributed to martian perchlorate reactions with the MTBSTFA derivitization reagent (Glavin et al., 2013), and chlorobenzene and $C_{2}$ to $C_{4}$ dichloroalkanes detected are attributed to native martian organics reacting with martian perchlorates (Freissinet et al., 2015). Ongoing work to reduce the effects of perchlorates in situ with SAM has proven effective (Freissinet et al., 2018), and continued optimization of SAM's TMAH experiment includes assessing the impact of perchorates on fatty acid 
detection (Buch et al., 2018). Although chlorine is widespread across Mars (Keller et al., 2006), oxychlorine compounds may not be homogenously distributed, as recent findings from the Curiosity rover indicate that oxychlorine compounds have not been identified since before the Oudam drill site in the Murray formation (elevation -4436 m) (Archer et al., 2018). Although the disappearance of oxychlorine compounds does not correlate with a decrease in elemental $\mathrm{Cl}$, it indicates differences in the types of chlorinated compounds present. A lower perchlorate concentration in a given sample may allow for better organics detection and fewer chlorinated compounds in future SAM analyses. Additionally, if perchlorates are present and affect the detection of fatty acids, information about the molecular weights of the organics generated can still be used to distinguish between likely contamination (only low molecular weight organics) and likely indigenous organics (high molecular weight or a combination of high and low molecular weights) (Sephton et al., 2014).

4.2.13. Strengths and limitations of the SAM instrument and paths forward for future missions. Many parameters can be modified in SAM to optimize GC-MS analyses. These include cup and sample preheat (e.g., no treatment to cup preheat at $200-250^{\circ} \mathrm{C}$ to sample boil-off up to $c a$. $\left.320^{\circ} \mathrm{C}\right)$, pyrolysis temperature $\operatorname{ramp}\left(35^{\circ} \mathrm{C} \mathrm{min}^{-1}\right.$ up to $c a$. $70^{\circ} \mathrm{C} \mathrm{min}^{-1}$, with final temperatures $\mathrm{ca} .960^{\circ} \mathrm{C}$ ), and $\mathrm{GC}$ oven temperature ramp $\left(5-15^{\circ} \mathrm{C} \mathrm{min}^{-1}\right.$, with final temperatures $c a .250^{\circ} \mathrm{C}$ ). See the work of Freissinet et al. (2015) for details on SAM flight model operational parameters. These parameters will be tested on the highest-fidelity SAM-like systems at NASA Goddard Space Flight Center to optimize the TMAH experiment for operation on Mars.
As discussed previously, long-chain FAMEs that were detected with the flash pyrolysis method were often missing when analyzed with the SAM-like pyrolysis method. This lack of long-chain FAMEs may have been due to the slow ramp of the pyrolysis oven, which may have broken down long-chain FAMEs to shorter chains which are then readily detected. This side effect of the slower ramp method may not affect in situ SAM performance, as initial benchtop analyses with a spare GC5 column suggest that smaller and shorter-chain molecules are more likely to be detected with SAM at nominal operating conditions (Millan et al., 2016). In the Millan et al. (2016) experiments, the largest molecule detected with flight spare GC5 column is naphthalene (molar mass $=128 \mathrm{~g} \mathrm{~mol}^{-1}$ ), and the largest molecule detected with the flight model GC5 column is biphenyl (molar mass $=154 \mathrm{~g} \mathrm{~mol}^{-1}$ ).

Of SAM's six GC columns, GC4, GC1, and until recently GC5, are the most commonly used. Split runs have been developed that allow a sample to be put on two columns during one pyrolysis run, effectively getting two analyses for (almost) the energy and resource costs of one analysis. The TMAH experiment on SAM will likely be conducted using a split between GC4, which has retention times similar to GC5 but cannot exceed $\sim 190^{\circ} \mathrm{C}$, and $\mathrm{GC} 1$, which does not have a thermal conductivity detector (TCD) and can therefore be heated to $\sim 250^{\circ} \mathrm{C}$. To determine the largest FAME that could be detected with SAM, the retention time of the Supelco 37 FAME standard was determined on the flight spare GC4 column using SAM-like flow and GC oven ramps. The largest FAME detected with a $10^{\circ} \mathrm{C} \mathrm{min}^{-1} \mathrm{GC}$ ramp was $\mathrm{C}_{12: 0}$ (Fig. 9). The SAM GC4 run ends at $25 \mathrm{~min}$ due to a flight column temperature limit and a short $\sim 3$ min hold. New and creative approaches may be developed that

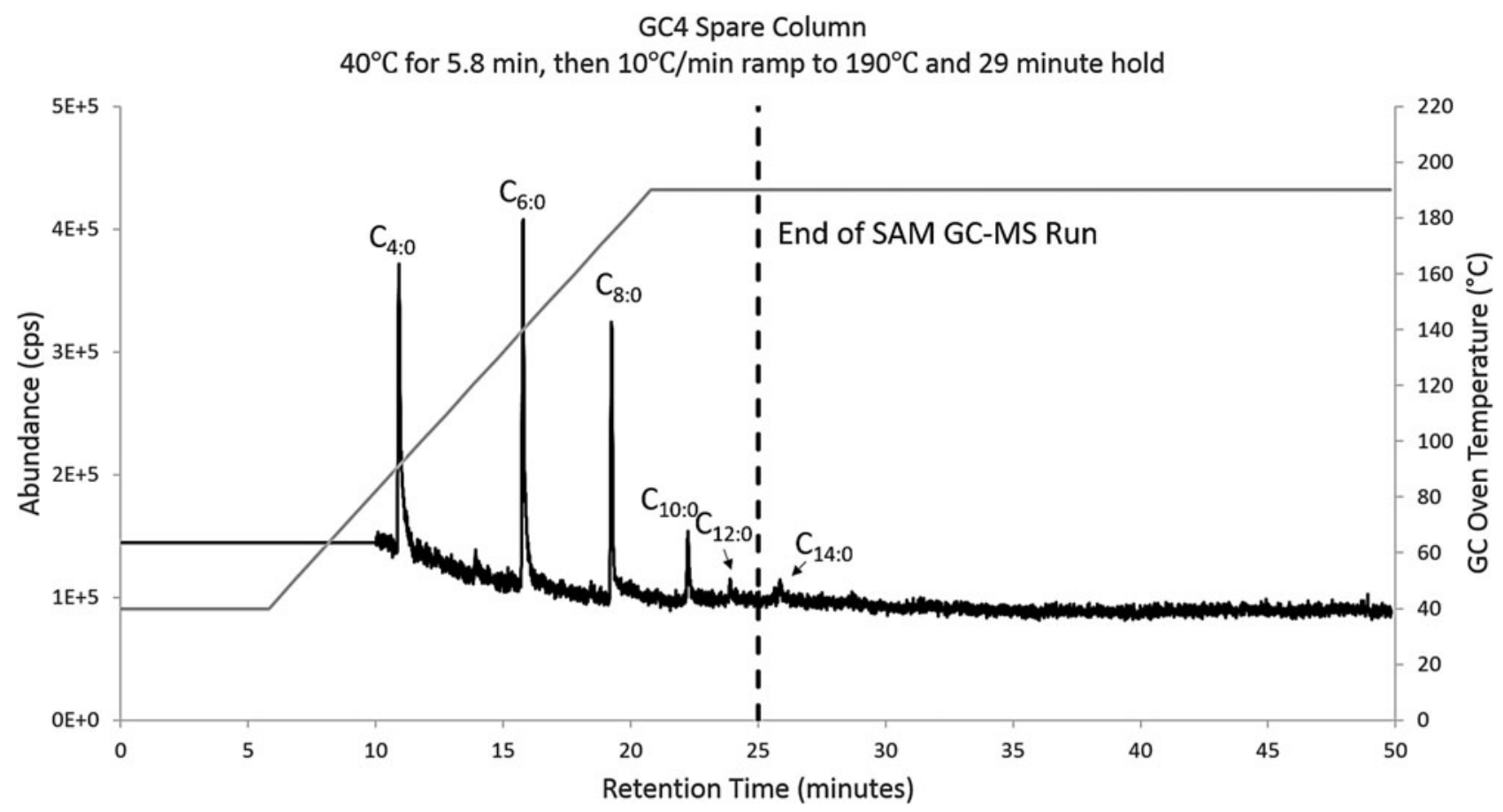

FIG. 9. Total ion chromatogram of the Supelco 37 FAME standard analyzed on the SAM spare GC4 column. Analysis

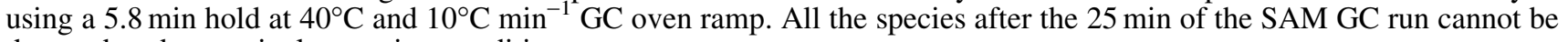
detected under nominal operating conditions. 
enable SAM to detect longer-chain FAMEs and determine the organic carbon sources and load on the martian surface and near-surface.

Other considerations for the in situ experiment include (1) the detection of other organic molecules beyond FAMEs associated with biologic origins and (2) the potential for radiation-induced decomposition of fatty acids. A complete summary of these topics is beyond the scope of this work and constitutes ongoing research in the field. In general, many other organic molecules may undergo thermochemolysis and be detected during the in situ experiment. For example, dicarboxylic acids such as those found in the Krebs cycle are detectable with this experiment and indeed have been previously detected in the Murchison meteorite (Lawless et al., 1974). The potential for radiation-induced decomposition of fatty acids is also important to note for this work. Radiolytic products of fatty acids tend to lose one carbon atom, which would change the biological fingerprint of the even-over-odd carbon number preference (Kim et al., 2004). However, any preference may be used to differentiate the FAME profile from an abiotic pattern with no carbon number preference.

The ExoMars rover will carry the MOMA instrument, which is also capable of detecting organic molecules with derivitization and thermochemolysis py-GC-MS experiments. MOMA will be able to ramp the pyrolysis oven at $>200^{\circ} \mathrm{C}$ $\mathrm{min}^{-1}$ (from thermal vacuum), achieving a much faster ramp than SAM and perhaps increasing the likelihood of detecting martian FAMEs, if present. Lessons learned from the operation of the wet chemistry experiments on SAM will be used to further optimize these experiments on MOMA.

\section{Conclusions}

This work represents the first analyses of a suite of Marsanalog samples using the TMAH experiment under select SAM-like conditions. The following experiment parameters were explored: sample exposure time to TMAH, TMAH reactions with MTBSTFA, and loss of the TMAH solvent methanol prior to sample pyrolysis. Samples may be exposed to TMAH and left to react in the SAM oven for up to $92 \mathrm{~h}$ and still yield detectable FAMEs when pyrolyzed. The MTBSTFA vapor known to be present in the SAM SMS will likely react somewhat with the in situ sample, yielding mixed methylated and silylated products that may increase the possibility of detecting fatty acids with SAM. Lastly, the predicted evaporation of $\mathrm{MeOH}$ from the TMAH/MeOH mixture will proceed slowly enough at the low operating temperatures and pressures on Mars that it should not significantly affect the in situ experiment.

Results from analog sample analyses demonstrated that fatty acids are readily methylated by TMAH to FAMEs and made detectable via py-GC-MS using a SAM-like pyrolysis ramp. Analog samples included iron oxyhydroxides/oxyhydroxysulfates, mixed iron oxide/oxyhydroxides and clay minerals, iron sulfides, siliceous sinter, carbonates, and shale. The TMAH experiments generally performed well under SAM-like pyrolyzer ramp conditions when organics were present and/or preserved in high concentrations, present from modern systems, and/or more preserved in circumneutral mixed mineralogy environments, although the experiments were capable of detecting FAMEs in all samples tested, albeit with a lower abundance and variety of
FAMEs. Analog samples were also tested with a flash pyrolysis method meant to reveal a more realistic representation of the organics loads in the analog samples. These flash pyrolysis experiments generated detectable FAMEs with a much higher abundance and greater variety of FAMEs, with results that were consistent with the SAM-like experiments.

Several unexpected results from the SAM-like and flash pyrolysis methods are applied to the continued optimization of the SAM thermochemolysis experiment. In the SAM-like $35^{\circ} \mathrm{C}$ $\mathrm{min}^{-1}$ pyrolysis ramp experiments, long-chain FAMEs, including the $n-\mathrm{C}_{19: 0}$ internal standard, were not consistently detected. The slow ramp at $35^{\circ} \mathrm{C} \mathrm{min}{ }^{-1}$ generates radicals and drives off the TMAH, and may have limited the time for reaction with the solid sample. Iron sulfide presented a unique challenge to thermochemolysis, and organics were not readily extracted from the pyrite sample in this work. The mineralogy of candidate samples for the in situ TMAH experiment will need to be well constrained before the experiment proceeds on Mars. The most promising mineralogies on which to perform the in situ experiment from this data set are the clay and mixed iron oxide/clay mineralogies, in which the oxidizing potential of the iron oxides appears to be diminished by the preservation potential of the clay minerals. Fe/Mg smectite clay minerals are present in the path of the Curiosity rover in the "clay-bearing unit" (Bennett et al., 2018) adjacent to the iron oxide-rich Vera Rubin Ridge, and these results indicate that the clay-bearing unit may provide the optimal opportunity to detect fatty acids, if present, in Gale Crater.

The TMAH thermochemolysis experiment on SAM represents a unique opportunity to detect organic molecules bound in macromolecules on Mars. The py-GC-MSgenerated FAME profile will be key to determining the genesis of fatty acids on Mars. The results from this study provide a framework for sample selection and experiment optimization for the SAM thermochemolysis experiments, as well as the development of the wet chemistry experiments on the ExoMars MOMA instrument.

\section{Acknowledgments}

Funding for the SAM GC was supported by the Centre National d'Etudes Spatiales and for the SAM Suite by the Science Mission Directorate of the National Aeronautics and Space Administration. Western Australian core samples were obtained through a drilling project funded by National Science Foundation EAR-0719822 grant to K.C.B. Iceland samples were obtained in part through funding by the Lewis and Clark Fund for Exploration and Field Research in Astrobiology to K.L.C. S.S.O.R. acknowledges support from the Marie Skłodowska-Curie Actions Programme and the Irish Research Council (ELEVATE Postdoctoral Fellowship ELEVATEPD/2014/47). The authors thank two anonymous reviewers and the extended SAM and Curiosity teams for helpful comments.

\section{Author Disclosure Statement}

No competing financial interests exist.

\section{References}

Albee, A.L., Arvidson, R.E., Palluconi, F., and Thorpe, T. (2001) Overview of the Mars Global Surveyor mission. $J$ Geophys Res: Planets 106:23291-23316. 
Anderson, R., Bridges, J.C., Williams, A., Edgar, L., Ollila, A., Williams, J., Nachon, M., Mangold, N., Fisk, M., Schieber, J., Gupta, S., Dromart, G., Wiens, R., Le Moulic, S., Forni, O., Lanza, N., Mezzacappa, A., Sautter, V., Blaney, D., Clark, B., Clegg, S., Gasnault, O., Lasue, J., Leveille, R., Lewin, E., Lewis, K.W., Maurice, S., Newsom, H., Schwenzer, S.P., and Vaniman, D. (2015) ChemCam results from the Shaler outcrop in Gale Crater, Mars. Icarus 249:2-21.

Archer, P.D., Ming, D.W., Sutter, B., Morris, R.V., Clark, B.C., Mahaffy, P.H., Wray, J.J., Fairen, A.G., Gellert, R., Yen, A., Blake, D.F., Vaniman, D.T., Glavin, D.P., Eigenbrode, J., Trainer, M.G., Navarro-González, R., McKay, C.P., Freissinet, C., and Martin, P. (2018) Oxychlorine detection in Gale Crater, Mars and implications for past environmental conditions [abstract P31F-3753]. In AGU 2018 Fall Meeting, American Geophysical Union, Washington, DC.

Atreya, S.K., Trainer, M.G., Franz, H.B., Wong, M.H., Manning, H.L.K., Malespin, C.A., Mahaffy, P.R., Conrad, P.G., Brunner, A.E., Leshin, L.A., Jones, J.H., Webster, C.R., Owen, T.C., Pepin, R.O., and Navarro-González, R. (2013) Primordial argon isotope fractionation in the atmosphere of Mars measured by the SAM instrument on Curiosity and implications for atmospheric loss. Geophys Res Lett 40:56055609.

Ben-David, E., Holden, P., Stone, D., Harch, B., and Foster, L. (2004) The use of phospholipid fatty acid analysis to measure impact of acid rock drainage on microbial communities in sediments. Microb Ecol 48:300-315.

Benison, K.C. and Bowen, B.B. (2006) Acid saline lake systems give clues about past environments and the search for life on Mars. Icarus 183:225-229.

Benison, K.C. and Bowen, B.B. (2015) The evolution of endmember continental waters: the origin of acidity in southern Western Australia. GSA Today 25:4-10.

Bennett, K.A., Fox, V.K., Vasavada, A.R., Grotzinger, J., Stack, K., Williams, A.J., Dehouck, E., and Edwards, C. (2018) Investigating the clay-bearing unit in Gale Crater with the Curiosity rover [abstract P21I-3437]. In $A G U 2018$ Fall Meeting, American Geophysical Union, Washington, DC.

Biemann, K., Oro, J., Toulmin, P., Orgel, L.E., Nier, A.O., Anderson, D.M., Simmonds, P.G., Flory, D., Diaz, A.V., Rushneck, D.R., and Biller, J.A. (1976) Search for organic and volatile inorganic compounds in two surface samples from the Chryse Planitia region of Mars. Science 194:72-76.

Biemann, K., Oro, J., Toulmin, P., III, Orgel, L.E., Nier, A.O., Anderson, D.M., Simmonds, P.G., Flory, D., Diaz, A.V., Rushneck, D.R., Biller, J.E., and Lafleur, A.L. (1977) The search for organic substances and inorganic volatile compounds in the surface of Mars. J Geophys Res 82:4641-4658.

Blokker, P., Schouten, S., de Leeuw, J.W., Sinninghe Damsté, J.S., and van den Ende, H. (2000) A comparative study of fossil and extant algaenans using ruthenium tetroxide degradation. Geochim Cosmochim Acta 64:2055-2065.

Bowen, B.B. and Benison, K.C. (2009) Geochemical characteristics of naturally acid and alkaline saline lakes in southern Western Australia. Appl Geochem 24:268-284.

Boynton, W.V., Bailey, S.H., Hamara, D.K., Williams, M.S., Bode, R.C., Fitzgibbon, M.R., Ko, W., Ward, M.G., Sridhar, K.R., Blanchard, J.A., Lorenz, R.D., May, R.D., Paige, D.A., Pathare, A.V., Kring, D.A., Leshin, L.A., Ming, D.W., Zent, A.P., Golden, D.C., Kerry, K.E., Lauer, H.V., and Quinn, R.C. (2001) Thermal and Evolved Gas Analyzer: part of the Mars Volatile and Climate Surveyor integrated payload. $J$ Geophys Res: Planets 106:17683-17698.
Boynton, W.V., Ming, D.W., Kounaves, S.P., Young, S.M.M., Arvidson, R.E., Hecht, M.H., Hoffman, J., Niles, P.B., Hamara, D.K., Quinn, R.C., Smith, P.H., Sutter, B., Catling, D.C., and Morris, R.V. (2009) Evidence for calcium carbonate at the Mars Phoenix landing site. Science 325:61-64. Brady, A.L., Slater, G.F., Omelon, C.R., Southam, G., Druschel, G., Andersen, D.T., Hawes, I., Laval, B., and Lim, D.S.S. (2010) Photosynthetic isotope biosignatures in laminated micro-stromatolitic and non-laminated nodules associated with modern, freshwater microbialites in Pavilion Lake, B.C. Chem Geol 274:56-67.

Bray, E. and Evans, E. (1961) Distribution of $n$-paraffins as a clue to recognition of source beds. Geochim Cosmochim Acta 22:2-15.

Bridges, N.T., Sullivan, R., Newman, C.E., Navarro, S., van Beek, J., Ewing, R.C., Ayoub, F., Silvestro, S., Gasnault, O., Le Mouélic, S., Lapotre, M.G.A., and Rapin, W. (2017) Martian aeolian activity at the Bagnold Dunes, Gale Crater: the view from the surface and orbit. J Geophys Res: Planets 122:2077-2110.

Buch, A., Szopa, C., Freissinet, C., Millan, M., Williams, A.J., Williams, R., Glavin, D., Guzman, M., Eigenbrode, J., Malespin, C., Cabane, M., Coscia, D., Bonnet, J.-Y., Teinturier, S., Johnson, S., and Mahaffy, P. (2018) Systematic study of impact of perchlorate on the derivatization reagents (TMAH and MTBSTFA) onboard SAM [abstract P21I-3440]. In AGU 2018 Fall Meeting, American Geophysical Union, Washington, DC.

Cantrell, S., Casillas-Martinez, L., and Molina, M. (2006) Characterization of fungi from hypersaline environments of solar salterns using morphological and molecular techniques. Mycol Res 110:962-970.

Carter, J. and Poulet, F. (2012) Orbital identification of clays and carbonates in Gusev Crater. Icarus 219:250-253.

Chefetz, B., Chen, Y., Clapp, C.E., and Hatcher, P.G. (2000) Characterization of organic matter in soils by thermochemolysis using tetramethylammonium hydroxide (TMAH). Soil Sci Soc Am J 64:583-589.

Conrad, P.G., Eigenbrode, J.L., der Heydt, M.O., Mogensen, C.T., Canham, J., Harpold, D.N., Johnson, J., Errigo, T., Glavin, D.P., and Mahaffy, P.R. (2012) The Mars Science Laboratory Organic Check Material. Space Sci Rev 170:479-501.

Cousin, A., Dehouck, E., Meslin, P.-Y., Forni, O., Williams, A.J., Stein, N., Gasnault, O., Bridges, N., Ehlmann, B., Schröder, S., Payré, V., Rapin, W., Pinet, P., Sautter, V., Maurice, S., and Wiens, R.C. (2017) Geochemistry of the Bagnold Dune Field as observed by ChemCam and comparison with other aeolian deposits at Gale Crater. J Geophys Res: Planets 122:2144-2162.

Cronin, J., Pizzarello, S., Epstein, S., and Krishnamurthy, R. (1993) Molecular and isotopic analyses of the hydroxy acids, dicarboxylic acids, and hydroxydicarboxylic acids of the Murchison meteorite. Geochim Cosmochim Acta 57:47454752.

del Rio, J.C., Martin, F., and Gonzalez-Vila, F.J. (1996) Thermally assisted hydrolysis and alkylation as a novel pyrolytic approach for the structural characterization of natural biopolymers and geomacromolecules. Trends Anal Chem 15:70-79.

Deport, C., Lemee, L., and Ambles, A. (2006) Comparison between humic substances from soil and peats using TMAH and TEAAc thermochemolysis. Org Geochem 37:649-664.

Edgar, L.A., Gupta, S., Rubin, D.M., Lewis, K.W., Kocurek, G.A., Anderson, R.B., Bell, J.F., III, Dromart, G., Edgett, K.S., Grotzinger, J.P., Hardgrove, C., Kah, L.C., Leveille, R., Malin, M.C., Mangold, N., Milliken, R.E., Minitti, M., 
Palucis, M., Rice, M., Rowland, S.K., Schieber, J., Stack, K.M., Sumner, D.Y., Wiens, R.C., Williams, R.M.E., and Williams, A.J. (2017) Shaler: in situ analysis of a fluvial sedimentary deposit on Mars. Sedimentology 65:96-122.

Eglinton, G. and Hamilton, R.J. (1967) Leaf epicuticular waxes. Science 156:1322-1335.

Ehlmann, B.L., Mustard, J.F., Murchie, S.L., Poulet, F., Bishop, J.L., Brown, A.J., Calvin, W.M., Clark, R.N., Des Marais, D.J., Milliken, R.E., Roach, L.H., Roush, T.L., Swayze, G.A., and Wray, J.J. (2008) Orbital identification of carbonatebearing rocks on Mars. Science 322:1828-1832.

Eigenbrode, J., Glavin, D., Dworkin, J., Conrad, P., and Mahaffy, P. (2011) Thermochemolysis-a new sample preparation approach for the detection of organic components of complex macromolecules in Mars rocks via gas chromatography mass spectrometry in SAM on MSL [abstract 1460]. In $42^{\text {nd }}$ Lunar and Planetary Science Conference, Lunar and Planetary Institute, Houston.

Eigenbrode, J.L., Summons, R.E., Steele, A., Freissinet, C., Millan, M., Navarro-González, R., Sutter, B., McAdam, A.C., Franz, H.B., Glavin, D.P., Archer, P.D., Mahaffy, P.R., Conrad, P.G., Hurowitz, J.A., Grotzinger, J.P., Gupta, S., Ming, D.W., Sumner, D.Y., Szopa, C., Malespin, C., Buch, A., and Coll, P. (2018) Organic matter preserved in 3-billionyear-old mudstones at Gale Crater, Mars. Science 360:10961101.

Elias, V., Simoneit, B., and Cardoso, J. (1997) Even N-alkane predominances on the Amazon shelf and a northeast Pacific hydrothermal system. Naturwissenschaften 84:415-420.

Elvert, M., Boetius, A., Knittel, K., and Jorgensen, B. (2003) Characterization of specific membrane fatty acids as chemotaxonomic markers for sulfate-reducing bacteria involved in anaerobic oxidation of methane. Geomicrobiol $J$ 20:403419.

Földvári, M. (2011) Handbook of Thermogravimetric System of Minerals and Its Use in Geological Practice, Occasional Papers of the Geological Institute of Hungary 213, Geological Institute of Hungary (Magyar Állami Földtani Intézet), Budapest, Hungary.

Fraeman, A.A., Arvidson, R.E., Catalano, J.G., Grotzinger, J.P., Morris, R.V., Murchie, S.L., Stack, K.M., Humm, D.C., McGovern, J.A., Seelos, F.P., Seelos, K.D., and Viviano, C.E. (2013) A hematite-bearing layer in Gale Crater, Mars: mapping and implications for past aqueous conditions. Geology 41:1103-1106.

Fraeman, A.A., Ehlmann, B.L., Arvidson, R.E., Edwards, C.S., Grotzinger, J.P., Milliken, R.E., Quinn, D.P., and Rice, M.S. (2016) The stratigraphy and evolution of lower Mount Sharp from spectral, morphological, and thermophysical orbital data sets. J Geophys Res: Planets 121:1713-1736.

Freissinet, C., Glavin, D.P., Mahaffy, P.R., Miller, K.E., Eigenbrode, J.L., Summons, R.E., Brunner, A.E., Buch, A., Szopa, C., Archer, P.D., Jr., Franz, H.B., Atreya, S.K., Brinckerhoff, W.B., Cabane, M., Coll, P., Conrad, P.G., Des Marais, D.J., Dworkin, J.P., Fairén, A.G., François, P., Grotzinger, J.P., Kashyap, S., ten Kate, I.L., Leshin, L.A., Malespin, C.A., Martin, M.G., Martin-Torres, F.J., McAdam, A.C., Ming, D.W., Navarro-González, R., Pavlov, A.A., Prats, B.D., Squyres, S.W., Steele, A., Stern, J.C., Sumner, D.Y., Sutter, B., Zorzano, M.P., and the MSL Science Team. (2015) Organic molecules in the Sheepbed Mudstone, Gale Crater, Mars. J Geophys Res: Planets 120:495-514.

Freissinet, C., Glavin, D.P., Szopa, C., Buch, A., Eigenbrode, J., Millan, M., Sutter, B., Teinturier, S., Malespin, C.A., and
Mahaffy, P. (2018) SAM and the organic matter in Gale Crater, Mars-inventory and implications [abstract P13A03]. In $A G U 2018$ Fall Meeting, American Geophysical Union, Washington, DC.

Gelpi, E., Han, L., Nooner, D., and Oro, J. (1970) Closed system Fischer-Tropsch synthesis over meteoritic iron, iron ore and nickel-iron alloy. Geochim Cosmochim Acta 34:965-979.

Georgiou, C.D. and Deamer, D.W. (2014) Lipids as universal biomarkers of extraterrestrial life. Astrobiology 14:541-549.

Glavin, D.P., Freissinet, C., Miller, K.E., Eigenbrode, J.L., Brunner, A.E., Buch, A., Sutter, B., Archer, P.D., Jr., Atreya, S.K., Brinckerhoff, W.B., Cabane, M., Coll, P., Conrad, P.G., Coscia, D., Dworkin, J.P., Franz, H.B., Grotzinger, J.P., Leshin, L.A., Martin, M.G., McKay, C., Ming, D.W., NavarroGonzález, R., Pavlov, A., Steele, A., Summons, R.E., Szopa, C., Teinturier, S., and Mahaffy, P.R. (2013) Evidence for perchlorates and the origin of chlorinated hydrocarbons detected by SAM at the Rocknest aeolian deposit in Gale Crater. J Geophys Res: Planets 118:1955-1973.

Goesmann, F., Brinckerhoff, W.B., Raulin, F., Goetz, W., Danell, R.M., Getty, S.A., Siljeström, S., Mißbach, H., Steininger, H., Arevalo, R.D., Jr., Buch, A., Freissinet, C., Grubisic, A., Meierhenrich, U.J., Pinnick, V.T., Stalport, F., Szopa, C., Vago, J.L., Lindner, R., Schulte, M.D., Brucato, J.R., Glavin, D.P., Grand, N., Xiang, L., van Amerom, F.H.W., and the MOMA Science Team. (2017) The Mars Organic Molecule Analyzer (MOMA) instrument: characterization of organic material in martian sediments. Astrobiology 17:655-685.

Goetz, W., Brinckerhoff, W.B., Arevalo, R., Freissinet, C., Getty, S., Glavin, D.P., Siljeström, S., Buch, A., Stalport, F., Grubisic, A., Li, X., Pinnick, V., Danell, R., et al.; the MOMA Science Team. (2016) MOMA: the challenge to search for organics and biosignatures on Mars. Int J Astrobiol 15:239-250.

Goth, K., de Leeuw, J.W., Puttmann, W., and Tegelaar, E.W. (1988) Origin of messel oil shale kerogen. Nature 336:759761.

Govaert, A., Dauwe, C., Plinke, P., De Grave, E., and De Sitter, J. (1976) A classification of geothite minerals based on the Mossbauer behavior. J Phys Colloq 37:825-827.

Grasset, L., Guignard, C., and Amblès, A. (2002) Free and esterified aliphatic carboxylic acids in humin and humic acids from a peat sample as revealed by pyrolysis with tetramethylammonium hydroxide or tetraethylammonium acetate. Org Geochem 33:181-188.

Grimalt, J. and Albaiges, J. (1987) Sources and occurrence of $\mathrm{C}_{12}$ to $\mathrm{C}_{22} n$-alkane distributions with even carbon-number preference in sedimentary environments. Geochim Cosmochim Acta 51:1379-1384.

Grotzinger, J.P., Sumner, D.Y., Kah, L.C., Stack, K., Gupta, S., Edgar, L., Rubin, D., Lewis, K., Schieber, J., Mangold, N., Milliken, R., Conrad, P.G., Des Marais, D., Farmer, J., Siebach, K., Calef, F., Hurowitz, J., McLennan, S.M., Ming, D., Vaniman, D., Crisp, J., Vasavada, A., Edgett, K.S., Malin, M., Blake, D., Gellert, R., Mahaffy, P., Wiens, R.C., Maurice, S., Grant, J.A., Wilson, S., Anderson, R.C., Beegle, L., Arvidson, R., Hallet, B., Sletten, R.S., Rice, M., Bell, J., Griffes, J., Ehlmann, B., Anderson, R.B., Bristow, T.F., Dietrich, W.E., Dromart, G., Eigenbrode, J., Fraeman, A., Hardgrove, C., Herkenhoff, K., Jandura, L., Kocurek, G., Lee, S., Leshin, L.A., Leveille, R., Limonadi, D., Maki, J., McCloskey, S., Meyer, M., Minitti, M., Newsom, H., Oehler, D., Okon, A., Palucis, M., Parker, T., Rowland, S., Schmidt, M., Squyres, 
S., Steele, A., Stolper, E., Summons, R., Treiman, A., Williams, R., and Yingst, A. (2014) A habitable fluvio-lacustrine environment at Yellowknife Bay, Gale Crater, Mars. Science 343, doi:10.1126/science.1242777.

Guignard, C., Lemee, L., and Ambles, A. (2005) Lipid constituents of peat humic acids and humin. Distinction from directly extractable bitumen components using TMAH and TEAAc thermochemolysis. Org Geochem 36:287-297.

Guzman, M., McKay, C., Quinn, R., Szopa, C., Davila, A.F., Navarro-González, R., and Freissinet, C. (2018) Identification of chlorobenzene in the Viking gas chromatograph-mass spectrometer data sets: reanalysis of Viking mission data consistent with aromatic organic compounds on Mars. $J$ Geophys Res: Planets 123:1674-1683.

Haddad, R., Martens, C., and Farrington, J. (1992) Quantifying early diagenesis of fatty acids in a rapidly accumulating coastal marine sediment. Org Geochem 19:205-216.

Hayes, J.M., Takigiku, R., Ocampo, R., Callot, H., and Albrecht, P. (1987) Isotopic compositions and probable origins of organic molecules in the Eocene Messel shale. Nature 329: $48-51$.

Jacobs, J., Testa, S.M., Alpers, C.N., and Nordstrom, D.K. (2016) An overview of environmental impacts and mine reclamation efforts at Iron Mountain, Shasta County, California. In Applied Geology in California, edited by R. Anderson and H. Ferriz, Association of Environmental \& Engineering Geologists, Star Publishing Company, Belmont, CA, pp 427-446.

Keller, J.M., Boynton, W.V., Karunatillake, S., Baker, V., Dohm, J., Evans, L., Finch, M., Hahn, B., Hamara, D.K., Janes, D.M., Kerry, K.E., Newsom, H.E., Reedy, R.C., Sprague, A.L., Squyres, S.W., Starr, R.D., Taylor, J.G., and Williams, R.M.S. (2006) Equatorial and midlatitude distribution of chlorine measured by Mars Odyssey GRS. J Geophys Res: Planets 111, doi:10.1029/2006JE002679.

Kelly, J. and Scheibling, R. (2011) Fatty acids as dietary tracers in benthic food webs. Mar Ecol Prog Ser 446:1-22.

Kelly, J. and Scheibling, R. (2012) Fatty acids as dietary tracers in benthic food webs. Mar Ecol Prog Ser 446:1-22.

Kim, K.-S., Lee, J.-M., Seo, H.-Y., Kim, J.-H., Song, H.-P., Byun, M.-W., and Kwon, J.-H. (2004) Radiolytic products of irradiated authentic fatty acids and triacylglycerides. Radiat Phys Chem 71:47-51.

Klingelhofer, G., Morris, R.V., Bernhardt, B., Schroder, C., Rodionov, D.S., de Sousa, P.A., Jr., Yen, A., Gellert, R., Evlanov, E.N., Zubkov, B., Foh, J., Bonnes, U., Kankeleit, E., Gutlich, P., Ming, D.W., Renz, F., Wdowiak, T., Squyres, S.W., and Arvidson, R.E. (2004) Jarosite and hematite at Meridiani Planum from Opportunity's Mossbauer spectrometer. Science 306:1740-1745.

Larter, S.R. and Horsfield, B. (1993) Determination of structural components of kerogens by the use of analytical pyrolysis methods. In Organic Geochemistry: Principles and Applications, edited by M.H. Engel and S.A. Macko, Plenum Press, New York, pp 271-288.

Lawless, J.G., Zeitman, B., Pereira, W.E., Summons, R.E., and Duffield, A.M. (1974) Dicarboxylic acids in the Murchison meteorite. Nature 251:40-42.

Lewis, J.M.T., Watson, J.S., Najorka, J., Luong, D., and Sephton, M.A. (2015) Sulfate minerals: a problem for the detection of organic compounds on Mars? Astrobiology 15: 247-258.

Lewis, J.M.T., Najorka, J., Watson, J.S., and Sephton, M.A. (2018) The search for Hesperian organic matter on Mars: pyrolysis studies of sediments rich in sulfur and iron. Astrobiology 18:454-464.

Mahaffy, P.R., Webster, C.R., Cabane, M., Conrad, P.G., Coll, P., Atreya, S.K., Arvey, R., Barciniak, M., Benna, M., Bleacher, L., Brinckerhoff, W.B., Eigenbrode, J.L., Carignan, D., Cascia, M., Chalmers, R.A., Dworkin, J.P., Errigo, T., Everson, P., Franz, H., Farley, R., Feng, S., Frazier, G., Freissinet, C., Glavin, D.P., Harpold, D.N., Hawk, D., Holmes, V., Johnson, C.S., Jones, A., Jordan, P., Kellogg, J., Lewis, J., Lyness, E., Malespin, C.A., Martin, D.K., Maurer, J., McAdam, A.C., McLennan, D., Nolan, T.J., Noriega, M., Pavlov, A.A., Prats, B., Raaen, E., Sheinman, O., Sheppard, D., Smith, J., Stern, J.C., Tan, F., Trainer, M., Ming, D.W., Morris, R.V., Jones, J., Gundersen, C., Steele, A., Wray, J., Botta, O., Leshin, L.A., Owen, T., Battel, S., Jakosky, B.M., Manning, H., Squyres, S., Navarro-González, R., McKay, C.P., Raulin, F., Sternberg, R., Buch, A., Sorensen, P., KlineSchoder, R., Coscia, D., Szopa, C., Teinturier, S., Baffes, C., Feldman, J., Flesch, G., Forouhar, S., Garcia, R., Keymeulen, D., Woodward, S., Block, B.P., Arnett, K., Miller, R., Edmonson, C., Gorevan, S., and Mumm, E. (2012) The Sample Analysis at Mars investigation and instrument suite. Space Sci Rev 170:401-478.

Mahaffy, P.R., Webster, C.R., Stern, J.C., Brunner, A.E., Atreya, S.K., Conrad, P.G., Domagal-Goldman, S., Eigenbrode, J.L., Flesch, G.J., Christensen, L.E., Franz, H.B., Freissinet, C., Glavin, D.P., Grotzinger, J.P., Jones, J.H., Leshin, L.A., Malespin, C., McAdam, A.C., Ming, D.W., Navarro-Gonzalez, R., Niles, P.B., Owen, T., Pavlov, A.A., Steele, A., Trainer, M.G., Williford, K.H., and Wray, J.J. (2015) The imprint of atmospheric evolution in the D/H of Hesperian clay minerals on Mars. Science 347:412-414.

Mangold, N., Thompson, L.M., Forni, O., Williams, A.J., Fabre, C., Le Deit, L., Wiens, R.C., Williams, R., Anderson, R.B., Blaney, D.L., Calef, F., Cousin, A., Clegg, S.M., Dromart, G., Dietrich, W.E., Edgett, K.S., Fisk, M.R., Gasnault, O., Gellert, R., Grotzinger, J.P., Kah, L., Le Mouélic, S., McLennan, S.M., Maurice, S., Meslin, P.-Y., Newsom, H.E., Palucis, M.C., Rapin, W., Sautter, V., Siebach, K.L., Stack, K., Sumner, D., and Yingst, A. (2016) Composition of conglomerates analyzed by the Curiosity rover: implications for Gale Crater crust and sediment sources. J Geophys Res: Planets 121:353-387.

Mangold, N., Schmidt, M.E., Fisk, M.R., Forni, O., McLennan, S.M., Ming, D.W., Sautter, V., Sumner, D., Williams, A.J., Clegg, S.M., Cousin, A., Gasnault, O., Gellert, R., Grotzinger, J.P., and Wiens, R.C. (2017) Classification scheme for sedimentary and igneous rocks in Gale Crater, Mars. Icarus 284:1-17.

McAdam, A.C., Franz, H.B., Sutter, B., Archer, P.D., Jr., Freissinet, C., Eigenbrode, J.L., Ming, D.W., Atreya, S.K., Bish, D.L., Blake, D.F., Bower, H.E., Brunner, A., Buch, A., Glavin, D.P., Grotzinger, J.P., Mahaffy, P.R., McLennan, S.M., Morris, R.V., Navarro- González, R., Rampe, E.B., Squyres, S.W., Steele, A., Stern, J.C., Sumner, D.Y., and Wray, J.J. (2014) Sulfur-bearing phases detected by evolved gas analysis of the Rocknest aeolian deposit, Gale Crater, Mars. J Geophys Res: Planets 119:373-393.

McCollom, T.M., Ritter, G., and Simoneit, B.R. (1999) Lipid synthesis under hydrothermal conditions by Fischer-Tropsch type reactions. Orig Life Evol Biosph 29:153-166.

McLennan, S.M., Anderson, R.B., Bell, J.F., Bridges, J.C., Calef, F., Campbell, J.L., Clark, B.C., Clegg, S., Conrad, P., Cousin, A., Des Marais, D.J., Dromart, G., Dyar, M.D., 
Edgar, L.A., Ehlmann, B.L., Fabre, C., Forni, O., Gasnault, O., Gellert, R., Gordon, S., Grant, J.A., Grotzinger, J.P., Gupta, S., Herkenhoff, K.E., Hurowitz, J.A., King, P.L., Le Mouelic, S., Leshin, L.A., Leveille, R., Lewis, K.W., Mangold, N., Maurice, S., Ming, D.W., Morris, R.V., Nachon, M., Newsom, H.E., Ollila, A.M., Perrett, G.M., Rice, M.S., Schmidt, M.E., Schwenzer, S.P., Stack, K., Stolper, E.M., Sumner, D.Y., Treiman, A.H., VanBommel, S., Vaniman, D.T., Vasavada, A., Wiens, R.C., and Yingst, R.A. (2014) Elemental geochemistry of sedimentary rocks at Yellowknife Bay, Gale Crater, Mars. Science 343, doi:10.1126/science.1244734.

Metcalffe, L.D. and Wang, C.N. (1981) Rapid preparation of fatty acid methyl esters using organic base-catalyzed transesterification. J Chromatogr Sci 19:530-535.

Michalski, J.R. and Niles, P.B. (2010) Deep crustal carbonate rocks exposed by meteor impact on Mars. Nat Geosci 3:751755.

Millan, M., Szopa, C., Buch, A., Coll, P., Glavin, D.P., Freissinet, C., Navarro-Gonzalez, R., François, P., Coscia, D., Bonnet, J.Y., Teinturier, S., Cabane, M., and Mahaffy, P.R. (2016) In situ analysis of martian regolith with the SAM experiment during the first Mars year of the MSL mission: identification of organic molecules by gas chromatography from laboratory measurements. Planet Space Sci 129:88-102.

Ming, D.W., Lauer, H.V., Archer, P.D., Sutter, B., Golden, D.C., Morris, R.V., Niles, P.B., and Boynton, W.V. (2009) Combustion of organic molecules by the thermal decomposition of perchlorate salts: implications for organics at the Mars Phoenix Scout landing site [abstract 2241]. In $40^{\text {th }}$ Lunar and Planetary Science Conference Abstracts, Lunar and Planetary Institute, Houston.

Ming, D.W., Archer, P.D., Glavin, D.P., Eigenbrode, J.L., Franz, H.B., Sutter, B., Brunner, A.E., Stern, J.C., Freissinet, C., McAdam, A.C., Mahaffy, P.R., Cabane, M., Coll, P., Campbell, J.L., Atreya, S.K., Niles, P.B., Bell, J.F., Bish, D.L., Brinckerhoff, W.B., Buch, A., Conrad, P.G., Des Marais, D.J., Ehlmann, B.L., Fairén, A.G., Farley, K., Flesch, G.J., Francois, P., Gellert, R., Grant, J.A., Grotzinger, J.P., Gupta, S., Herkenhoff, K.E., Hurowitz, J.A., Leshin, L.A., Lewis, K.W., McLennan, S.M., Miller, K.E., Moersch, J., Morris, R.V., Navarro-González, R., Pavlov, A.A., Perrett, G.M., Pradler, I., Squyres, S.W., Summons, R.E., Steele, A., Stolper, E.M., Sumner, D.Y., Szopa, C., Teinturier, S., Trainer, M.G., Treiman, A.H., Vaniman, D.T., Vasavada, A.R., Webster, C.R., Wray, J.J., and Yingst, R.A. (2014) Volatile and organic compositions of sedimentary rocks in Yellowknife Bay, Gale Crater, Mars. Science 343, doi: 10.1126/science.1245267.

Morris, R.V., Ruff, S.W., Gellert, R., Ming, D.W., Arvidson, R.E., Clark, B.C., Golden, D.C., Siebach, K., Klingelhöfer, G., Schröder, C., Fleischer, I., Yen, A.S., and Squyres, S.W. (2010) Identification of carbonate-rich outcrops on Mars by the Spirit rover. Science 329:421-424.

Murchie, S.L., Mustard, J.F., Ehlmann, B.L., Milliken, R.E., Bishop, J.L., McKeown, N.K., Noe Dobrea, E.Z., Seelos, F.P., Buczkowski, D.L., Wiseman, S.M., Arvidson, R.E., Wray, J.J., Swayze, G., Clark, R.N., Des Marais, D.J., McEwen, A.S., and Bibring, J.-P. (2009) A synthesis of martian aqueous mineralogy after 1 Mars year of observations from the Mars Reconnaissance Orbiter. J Geophys Res: Planets 114, doi:10.1029/2009JE003342.

Mustard, J.F., Adler, M., Allwood, A., Bass, D.S., Beaty, D.W., Bell, J.F., III, Brinckerhoff, W.B., Carr, M., Des Marais, D.J.,
Drake, B., Edgett, K.S., Eigenbrode, J., Elkins-Tanton, L.T., Grant, J.A., Milkovich, S.M., Ming, D., Moore, C., Murchie, S., Onstott, T.C., Ruff, S.W., Sephton, M.A., Steele, A., and Treiman, A. (2013) Report of the Mars 2020 Science Definition Team by the Mars Exploration Program Analysis Group (MEPAG), 154 pp, posted July, 2013, by the Mars Exploration Program Analysis Group (MEPAG) at http:// mepag.jpl.nasa.gov/reports/MEP/Mars_2020_SDT_Report_ Final.pdf

Navarro-González, R., Vargas, E., de la Rosa, J., Raga, A.C., and McKay, C.P. (2010) Reanalysis of the Viking results suggests perchlorate and organics at midlatitudes on Mars. $J$ Geophys Res: Planets 115, doi:10.1029/2010JE003599.

Navarro-González, R., Vargas, E., de la Rosa, J., Raga, A.C., and McKay, C.P. (2011) Correction to "Reanalysis of the Viking results suggests perchlorate and organics at midlatitudes on Mars." J Geophys Res: Planets 116, doi:10.1029/ 2011JE003854.

Nishimura, M. and Baker, E. (1986) Possible origin of $n$-alkanes with a remarkable even-to-odd predominance in recent marine sediments. Geochim Cosmochim Acta 50:299-305.

O'Reilly, S.S., Mariotti, G., Winter, A.R., Newman, S.A., Matys, E.D., McDermott, F., Pruss, S.B., Bosak, T., Summons, R.E., and Klepac-Ceraj, V. (2017) Molecular biosignatures reveal common benthic microbial sources of organic matter in ooids and grapestones from Pigeon Cay, The Bahamas. Geobiology 15:112-130.

Parenteau, M.N., Jahnke, L.L., Farmer, J.D., and Cady, S.L. (2014) Production and early preservation of lipid biomarkers in iron hot springs. Astrobiology 14:502-521.

Pulchan, J., Abrajano, T.A., and Helleur, R. (1997) Characterization of tetramethylammonium hydroxide thermochemolysis products of near-shore marine sediments using gas chromatography/mass spectrometry and gas chromatography/combustion/isotope ratio mass spectrometry. J Anal Appl Pyrolysis 42:135-150.

Remusat, L., Derenne, S., Robert, F., and Knicker, H. (2005) New pyrolytic and spectroscopic data on Orgueil and Murchison insoluble organic matter: a different origin than soluble? Geochim Cosmochim Acta 69:3919-3932.

Ritchie, N.J., Schutter, M.E., Dick, R.P., and Myrold, D.D. (2000) Use of length heterogeneity PCR and fatty acid methyl ester profiles to characterize microbial communities in soil. Appl Environ Microbiol 66:1668-1675.

Ruff, S.W., Niles, P.B., Alfano, F., and Clarke, A.B. (2014) Evidence for a Noachian-aged ephemeral lake in Gusev Crater, Mars. Geology 42:359-362.

Schulten, H.R. (1996) Direct pyrolysis-mass spectrometry of soils: a novel tool in agriculture, ecology, forestry and soil science. In Mass Spectrometry of Soils, edited by S. Yamasaki and T.W. Boutton, Marcel Dekker, New York, pp 373-436.

Schummer, C., Delhomme, O., Appenzeller, B.M., Wenning, R., and Millet, M. (2009) Comparison of MTBSTFA and BSTFA in derivatization reactions of polar compounds prior to GC/MS analysis. Talanta 77:1473-1482.

Sephton, M.A., Lewis, J.M.T., Watson, J., Montgomery, W., and Garnier, C. (2014) Perchlorate-induced combustion of organic matter with variable molecular weights: implications for Mars missions. Geophys Res Lett 41:7453-7460.

Skok, J.R. (2010) Silica deposits in the Nili Patera caldera on the Syrtis Major volcanic complex on Mars. Nat Geo 3:838841.

Stalport, F., Glavin, D.P., Eigenbrode, J.L., Bish, D.L., Blake, D.F., Coll, P., Szopa, C., Buch, A., McAdam, A., Dworkin, 
J.P., and Mahaffy, P. (2012) The influence of mineralogy on recovering organic acids from Mars analogue materials using the " "one-pot", derivatization experiment on the Sample Analysis at Mars (SAM) instrument suite. Planet Space Sci 67:1-13.

Summons, R.E., Albrecht, P., McDonald, G., and Moldowan, J.M. (2008) Molecular biosignatures. Space Sci Rev 135:133159.

Sumner, D.Y. (2004) Poor preservation potential of organics in Meridiani Planum hematite-bearing sedimentary rocks. $J$ Geophys Res: Planets 109, doi:10.1029/2004JE002321.

Sun, M.-Y., Wakeham, S., and Lee, C. (1997) Rates and mechanisms of fatty acid degradation in oxic and anoxic coastal marine sediments of Long Island Sound, New York, USA. Geochim Cosmochim Acta 61:341-355.

Sutter, B., McAdam, A.C., Mahaffy, P.R., Ming, D.W., Edgett, K.S., Rampe, E.B., Eigenbrode, J.L., Franz, H.B., Freissinet, C., Grotzinger, J.P., Steele, A., House, C.H., Archer, P.D., Malespin, C.A., Navarro-González, R., Stern, J.C., Bell, J.F., Calef, F.J., Gellert, R., Glavin, D.P., Thompson, L.M., and Yen, A.S. (2017) Evolved gas analyses of sedimentary rocks and eolian sediment in Gale Crater, Mars: results of the Curiosity rover's Sample Analysis at Mars (SAM) instrument from Yellowknife Bay to the Namib Dune. J Geophys Res: Planets 122:2574-2609.

Tan, J., Lewis, J.M.T., and Sephton, M.A. (2018) The fate of lipid biosignatures in a Mars-analogue sulfur stream. Sci Rep 8, doi:10.1038/s41598-018-25752-7.

Vaniman, D.T., Bish, D.L., Ming, D.W., Bristow, T.F., Morris, R.V., Blake, D.F., Chipera, S.J., Morrison, S.M., Treiman, A.H., Rampe, E.B., Rice, M., Achilles, C.N., Grotzinger, J.P., McLennan, S.M., Williams, J., Bell, J.F., III, Newsom, H.E., Downs, R.T., Maurice, S., Sarrazin, P., Yen, A.S., Morookian, J.M., Farmer, J.D., Stack, K., Milliken, R.E., Ehlmann, B.L., Sumner, D.Y., Berger, G., Crisp, J.A., Hurowitz, J.A., Anderson, R., Des Marais, D.J., Stolper, E.M., Edgett, K.S., Gupta, S., Spanovich, N., and the MSL Science Team. (2014) Mineralogy of a mudstone at Yellowknife Bay, Gale Crater, Mars. Science 343, doi:10.1126/science.1243480.

Vestal, J.R. and White, D.C. (1989) Lipid analysis in microbial ecology. Bioscience 39:535-541.

Volkman, J. (2006) Lipid biomarkers for marine organic matter. In Marine Organic Matter: Biomarkers, Isotopes and DNA, edited by J. Volkman, Springer-Verlag, Berlin, pp 27-70.

Volkman, J., Jeffrey, S., Nichols, P., Rogers, G., and Farland, C. (1989) Fatty acid and lipid composition of 10 species of microalgae used in mariculture. J Exp Mar Bio Ecol 128: 219-240.

Volkman, J., Barrett, S., Blackburn, S., Mansour, M., Sikes, E., and Gelin, F. (1998) Microalgal biomarkers: a review of recent research developments. Org Geochem 29:1163-1179.

Wilhelm, M.B., Davila, A.F., Eigenbrode, J.L., Parenteau, M.N., Jahnke, L.L., Liu, X., Summons, R.E., Wray, J.J., Stamos, B.N., O'Reilly, S.S., and Williams, A.J. (2017) Xeropreservation of functionalized lipid biomarkers in hyperarid soils in the Atacama Desert. Org Geochem 103:97-104.

Williams, A.J., Sumner, D.Y., Alpers, C.N., Karunatillake, S., and Hofmann, B.A. (2015) Preserved filamentous microbial biosignatures in the Brick Flat gossan, Iron Mountain, California. Astrobiology 15:637-668.

Williams, A.J., Alpers, C., Sumner, D., and Campbell, K. (2017) Filamentous hydrous ferric oxide biosignatures in a pipeline carrying acid mine drainage at Iron Mountain Mine, California. Geomicrobiol J 34:193-206.

Williams, R.M.E., Grotzinger, J.P., Dietrich, W.E., Gupta, S., Sumner, D.Y., Wiens, R.C., Mangold, N., Malin, M.C., Edgett, K.S., Maurice, S., Forni, O., Gasnault, O., Ollila, A., Newsom, H.E., Dromart, G., Palucis, M.C., Yingst, R.A., Anderson, R.B., Herkenhoff, K.E., Le Mouélic, S., Goetz, W., Madsen, M.B., Koefoed, A., Jensen, J.K., Bridges, J.C., Schwenzer, S.P., Lewis, K.W., Stack, K.M., Rubin, D., Kah, L.C., Bell, J.F., III, Farmer, J.D., Sullivan, R., van Beek, T., Blaney, D.L., Pariser, O., and Deen, R.G. (2013) Martian fluvial conglomerates at Gale Crater. Science 291:1068-1072.

Yani, S. and Zhang, D. (2010) An experimental study into pyrite transformation during pyrolysis of Australian lignite samples. Fuel 89:1700-1708.

Zelles, L. (1999) Fatty acid patterns of phospholipids and lipopolysaccharides in the characterisation of microbial communities in soil: a review. Biol Fertil Soils 29:111-129.

Address correspondence to: Amy J. Williams 241 Williamson Hall University of Florida Gainesville, FL 32611

E-mail: amywilliams1@ufl.edu

Submitted 8 January 2018 Accepted 14 January 2019

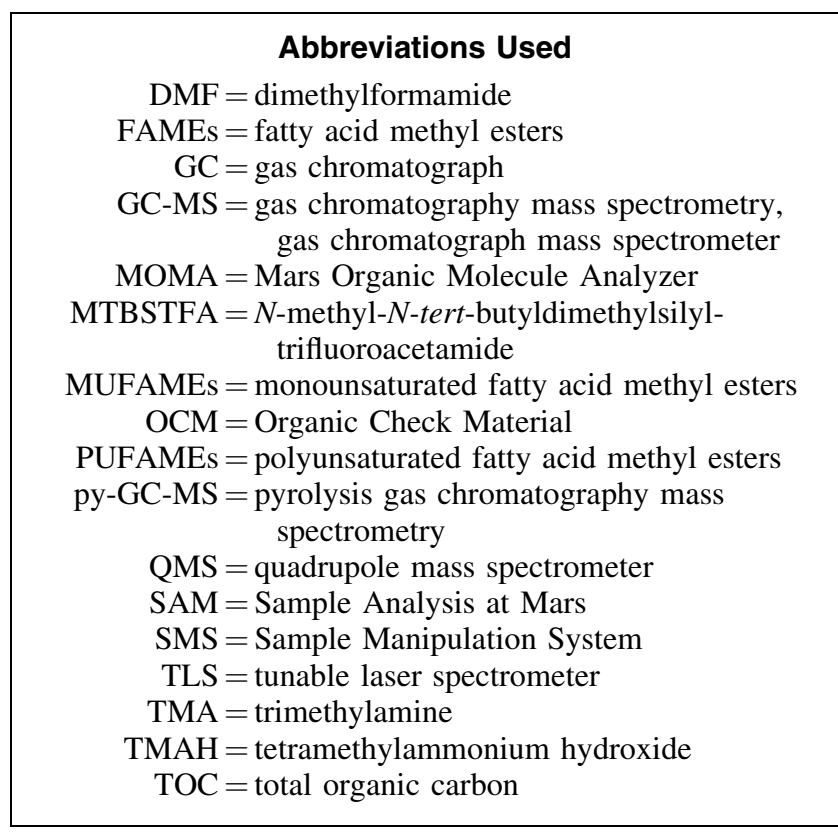

